\title{
Phase Behavior Identification and Formation Mechanisms of the BZ19-6 Condensate Gas Reservoir in the Deep Bozhong Sag, Bohai Bay Basin, Eastern China
}

\author{
Zhenliang Wang $\mathbb{C D}^{1,2}$ Shengdong Xiao, ${ }^{1,2}$ Feilong Wang, ${ }^{3}$ Guomin Tang, ${ }^{3}$ Liwen Zhu, ${ }^{1,2}$ \\ and Zilong Zhao ${ }^{1,2}$ \\ ${ }^{1}$ State Key Laboratory of Continental Dynamics (Northwest University), Xi'an, Shaanxi 710069, China \\ ${ }^{2}$ Department of Geology, Northwest University, Xi'an, Shaanxi 710069, China \\ ${ }^{3}$ Tianjin Branch of China National Offshore Oil Limited Corporation, Tianjin 300452, China
}

Correspondence should be addressed to Zhenliang Wang; 1105310783@qq.com

Received 14 December 2020; Revised 19 May 2021; Accepted 9 June 2021; Published 5 July 2021

Academic Editor: Yunpeng Wang

Copyright (c) 2021 Zhenliang Wang et al. This is an open access article distributed under the Creative Commons Attribution License, which permits unrestricted use, distribution, and reproduction in any medium, provided the original work is properly cited.

\begin{abstract}
Significant developments have been observed in recent years, in the field of deep part exploration in the Bozhong Sag, Bohai Bay Basin in eastern China. The BZ19-6 large condensate gas field, the largest gas field in the Bohai Bay Basin, was discovered for the first time in a typical oil-type basin. The proven oil and gas geological reserves in the deeply buried hills of the Archean metamorphic rocks, amount to approximately $3 \times 10^{8}$ tons of oil equivalent. However, the phase behavior and genetic mechanisms of hydrocarbon fluids are still unclear. In this study, the phase diagram identification method and various empirical statistical methods, such as the block diagram method, $\varphi_{1}$ parameter method, rank number method, and $Z$-factor method were implemented to comprehensively identify the phase behavior types of the BZ19-6 condensate gas reservoir. The genetic mechanism of the BZ19-6 condensate gas reservoir was investigated in detail through analyses of physical properties of the fluid at high temperatures and pressures, organic geochemical characteristics of condensate oil and gas, and regional tectonic background. Consequently, this study is shown as follows: (1) The BZ19-6 condensate gas reservoir is a part of a secondary condensate gas reservoir with oil rings, formed synthetically since the Neogene period due to multiple factors, such as retrograde evaporation from deep burial and high temperature, inorganic $\mathrm{CO}_{2}$ charging from the deep mantle, and late natural gas invasion. (2) The hydrocarbon accumulation process of the BZ19-6 condensate gas reservoir is as follows: First, a large amount of oil is accumulated at the end of the lower Minghuazhen deposition (5 Ma BP); second, a large amount of natural gas is generated in the deep-source kitchen and mantle-derived inorganic $\mathrm{CO}_{2}$ charged into the early formed oil reservoirs at the end of the upper Minghuazhen deposition (2 Ma BP). As a result, the content of gaseous hydrocarbons in the hydrocarbon system of the reservoir increased, which led to large amounts of liquid hydrocarbons dissolved in gaseous hydrocarbons and significantly reduced the critical temperature of the hydrocarbon system. Therefore, existing secondary condensate gas reservoirs are formed when the critical temperature is lower than the formation temperature and it enters the critical condensate temperature range.
\end{abstract}

\section{Introduction}

A series of deep of strata and deep water and unconventional areas represent the global development trends of oil and gas exploration [1-3]. Deep oil and gas are the most suitable replacement fields for hydrocarbon exploration in China and the world $[2,3]$. The Bohai Bay Basin is recognized as one of the two super petroliferous basins in China and is a typical oil-type basin $[4,5]$. In recent years, a strategic breakthrough has been achieved pertaining to the deep gas exploration in the Bohai Bay Basin. The proven oil and gas geological reserves of the first discovered BZ19-6 large condensate gas field in the deeply buried hills of the Archean metamorphic rocks, amounted to an approximate equivalent 
of $3 \times 10^{8}$ tons of oil (according to http://www.china.com.cn, 2020-1-10 14:16). Here, the proven gas geological reserve and the proven condensate oil geological reserve amounted to more than $1 \times 10^{8} \mathrm{~m}^{3}$ each, revealing immense exploration potential of deep gas $[4,6]$. The existence of large deep gas reservoirs in the Bozhong Sag can be attributed to certain favorable conditions. First, the Bozhong Sag is the most likely source kitchen to form large gas fields, with a high hydrocarbon potential and thermal maturity $[5,7]$. Second, the Bozhong Sag exhibits favorable petroleum geological conditions with several sets of reservoir-cap assemblages $[8,9]$. In addition, the regional thick mudstone of the Dongying Formation is favorable for deep hydrocarbon accumulation [4-6, 8, 9].

It was found that the BZ19-6 deep buried hill gas reservoir is a condensate gas reservoir. A condensate gas reservoir is a special hydrocarbon deposit located between oil and gas reservoirs and is more valuable compared with conventional oil and gas reservoirs. Condensate gas exhibits the characteristics of complex genesis, complex thermodynamics, and multiple phase behaviors [10-13], of which phase behavior and formation mechanism are of great significance in the evaluation of deep oil and gas resources. The study on the phase behavior of condensate gas reservoirs began in the 1930s. A large number of gas-liquid state experiments have expanded our understanding of condensate oil and gas and have promoted further research and development of condensate gas reservoirs $[14,15]$. A majority of the condensate oil and gas, which is the product of organic matter formed in the higher maturity stage $\left(R_{\mathrm{o}}>1.3 \%\right)$, higher temperature, and higher pressure environment, are initially generated in the late hypogenic stage. In addition, condensate gas is directly generated by the resin component of type III kerogen in the immature stage $\left(0.4 \%<R_{\mathrm{o}}<0.6 \%\right)$ [16-18]. Secondly, the chemical composition and temperature-pressure system of hydrocarbon systems are the key factors controlling the hydrocarbon phase behavior [17-22]; multiple sets of source rocks and multiple stages of hydrocarbon migration along with secondary alteration after hydrocarbon accumulation lead to diversity in the hydrocarbon phase behavior and complexity in its genesis [23]. The condensate gas reservoirs can be classified as primary and secondary, among which the secondary type can be subdivided into crude oil cracking, migration fractionation, and gas invasion and enrichment types.

The BZ19-6 large condensate gas reservoir possesses the following characteristics: humic-sapropelic and kerogencracking gases are the origin gas, the gas field has a large gas thickness and high gas column, and the accumulation process began with oil, followed by gas [8]. The hydrocarbon accumulation process of "early oil and late gas" was characterized by near-source early oil and late gas continuous charging, in which the crude oil and the natural gas was charged at $12-5.1 \mathrm{Ma} \mathrm{BP}$ and $5.1-0 \mathrm{Ma} \mathrm{BP}$, respectively [24]. Phase-controlled miscibility is the main formation mechanism of condensate gas in the BZ19-6 structure; when the local temperature and pressure rise, the early crude oil dissolves in the late charging natural gas and forms the present condensate gas reservoir $[25,26]$. However, phasecontrolled miscibility cannot completely explain the genesis and formation processes of the BZ19-6 condensate gas reser- voirs. Moreover, the deep oil and gas phase behavior affects the migration mode and accumulation mechanism and influences the direction of deep oil and gas exploration, restricting the evaluation of oil and gas resources in deep condensate gas reservoirs. Based on the composition of the BZ19-6 condensate gas and the oil test results, the phase behavior types of the condensate gas reservoir were comprehensively identified using various methods. The formation mechanism of the condensate gas reservoir and its hydrocarbon accumulation process were systematically analyzed based on previous studies of sedimentary and tectonic evolution characteristics and key hydrocarbon accumulation elements in this area. The results of our study can potentially guide future resource evaluation of deep condensate gas reservoirs in the Bozhong Sag and development of deep hydrocarbon accumulation in the geological theory.

\section{Petroleum Geological Background}

The BZ19-6 condensate gas field is an anticlinal uplift located on the deep structural ridge in the southwest of the Bozhong Sag, adjacent to the Chengbei low uplift in the west, the Bonan low uplift in the southeast, the Shaleitian uplift in the north, and the main subsag in the northeast (Figure 1). Drilling revealed that the BZ19-6 and CFD18 structures in the north are both direct outcropping areas of the Archean. The strata in the BZ19-6 structure from new to old includes the Neogene Minghuazhen Formation (Fm.) ( $\left.\mathrm{N}_{2} \mathrm{~m}\right)$, Guantao Fm. $\left(\mathrm{N}_{1} \mathrm{~g}\right)$, Paleogene Dongying Fm. $\left(\mathrm{E}_{3} \mathrm{~d}\right)$, Shahejie Fm. $\left(\mathrm{E}_{2} \mathrm{~s}\right)$, Kongdian Fm. $\left(\mathrm{E}_{1-2} \mathrm{k}\right)$, and the Archaeozoic Fm. (Ar). The $\mathrm{N}_{2} \mathrm{~m}$ is a mixed deposition of mudstone and sandstone, whereas the $\mathrm{N}_{1}$ g primarily comprises sandstone; both are Neogene reservoirs. Both $\mathrm{E}_{3} \mathrm{~d}$ and $\mathrm{E}_{2} \mathrm{~s}$ primarily comprise dark mudstone and a small amount of sandstone, which are the major source rocks. $\mathrm{E}_{1-2} \mathrm{k}$ is primarily glutenite and reservoirs. The Ar is primarily a metamorphic rock buried hill, which is the main reservoir. From top to bottom, the strata can be divided into three sets of hydrocarbon accumulation assemblages: upper Neogene reservoir assemblage, middle Paleogene reservoir assemblage, and lower buried hill reservoir assemblage [5].

According to the structural characteristics, the BZ19-6 low buried hill is divided into south and north blocks in the plane, and strike-slip and extensional faults cut each other, forming several complex fault-block traps with anticline and broken noses. Vertically, it includes the single-layer structures of the Archean buried hill and the double-layer structures in the glutenite of the Kongdian Formation, with the highest point of the trap being between 3825 and 5475 $\mathrm{m}[8]$.

The metamorphic rocks of the Archean low buried hill and glutenite of the Kongdian Fm. overlying the low buried hill are both the primary gas-bearing strata of the BZ19-6 condensate gas reservoir. The lithology of the Archean reservoirs is primarily monzonitic gneiss, plagioclase gneiss, and mixed gneiss. The reservoir is dominated by fractures, along with the presence of dissolution pores. The porosity ranges from $2.7 \%$ to $12.8 \%$ and the permeability ranges from 0.01 to $11.81 \mathrm{mD}$ [4]. Since 2016, several wells have been drilled 


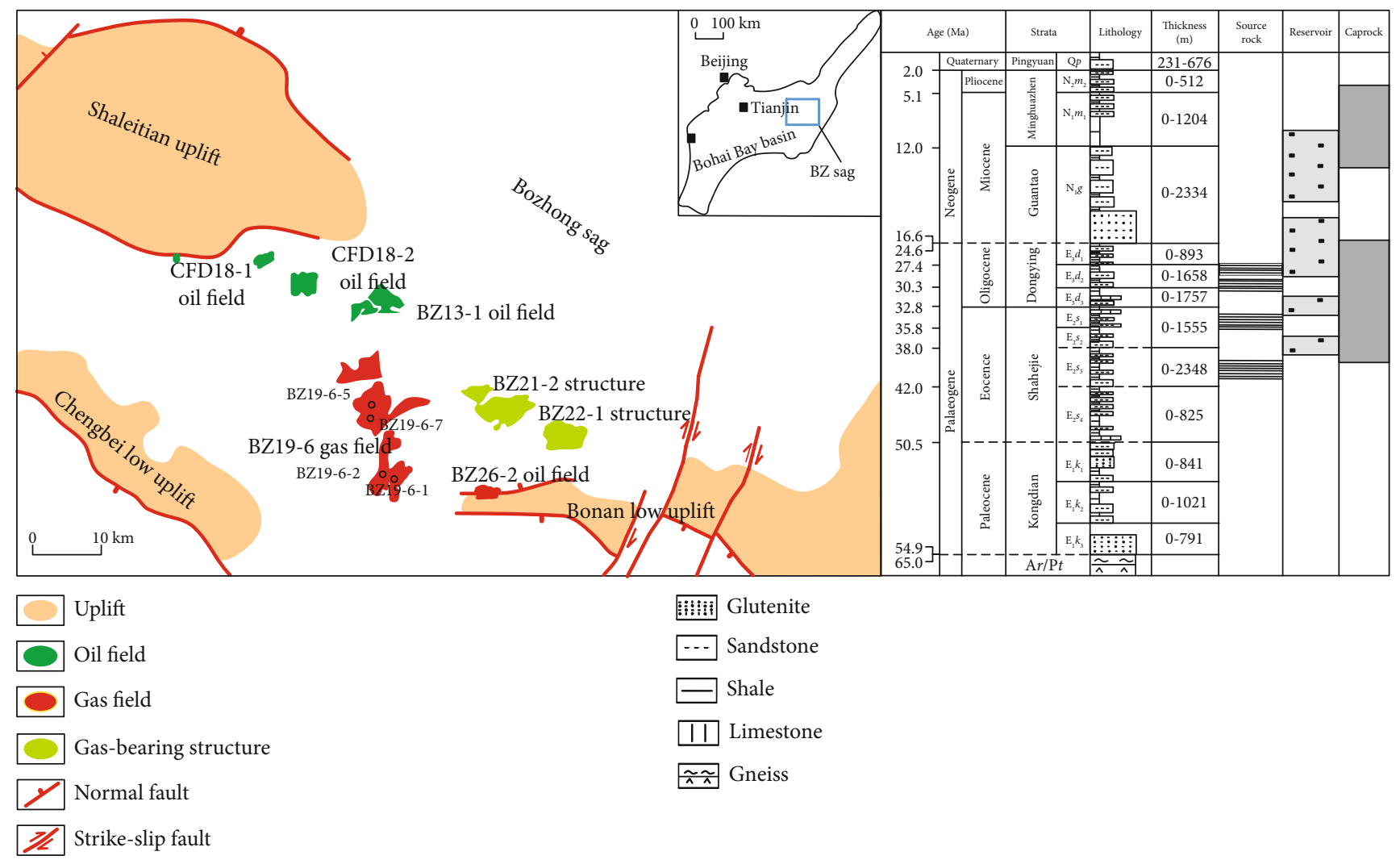

Figure 1: Geological location and comprehensive stratigraphic column of the BZ19-6 gas field in the deep Bozhong Sag. The structure comprises three buried hills. The major reservoir rocks are Archean or Proterozoic gneiss with two fracture developed zones and sandstone at the bottom of the Kongdian Fm. The discovered oil and gas are sourced from Shahejie Fm. $\left(\mathrm{E}_{2} \mathrm{~s}_{3}, \mathrm{E}_{2} \mathrm{~s}_{1}\right)$ and Dongying Fm. $\left(\mathrm{E}_{3} \mathrm{~d}\right)$ source rocks.

into the BZ19-6 structural belt and have exhibited good productivity. The highest daily gas production in the Kongdian Fm. and Archean region is $>30 \times 10^{4} \mathrm{~m}^{3}\left(600 \mathrm{~m}^{3} / \mathrm{d}\right.$ oil equivalent), the daily oil production is $>300 \mathrm{~m}^{3}$, and the gas-oil ratio (GOR) is $1023-1539 \mathrm{~m}^{3} / \mathrm{m}^{3}$ (Table 1). The average temperature of the Archean buried hill is $150.8^{\circ} \mathrm{C}$, and the geothermal gradient is $3.3^{\circ} \mathrm{C} / 100 \mathrm{~m}$. The average pressure is $47.46 \mathrm{MPa}$, and the pressure coefficient is $1.15-1.26$; this implies that the Archean buried hill is a weak overpressure condensate gas field.

\section{Methods and Results of Fluid Phase Identification}

The accurate identification of the condensate gas reservoir phase behavior type is related to the estimation of oil and gas reserves, optimization of the development mode, and evaluation of the production performance. The identification methods include the phase diagram and empirical statistical discrimination methods, among which the pressure-volume-temperature (PVT) experimental phase diagram discrimination method is the most reliable; however, the effort and cost of field sampling and experimental analysis associated with this method are relatively high. The empirical statistical discriminant method requires less data and is simple and easy to operate; however, it also has certain limitations. Therefore, a comprehensive analysis using both the methods should be considered. Several PVT experiments have been implemented for verification of existing experimental results; based on these PVT experiments, the phase pattern discriminant method along with several empirical statistical discriminant methods were used to comprehensively identify the phase behavior types of the BZ19-6 condensate gas reservoir. Moreover, PVTsim20 software was used to simulate the change characteristics of the hydrocarbon phase behavior with an increase in the $\mathrm{CH}_{4}$ and $\mathrm{CO}_{2}$ content.

The PVTsim20 software was used during numerical simulation; the P-R state equation, introducing Peneloux volume correction integrated with the thermodynamic theories and gas-liquid phase equilibrium equations, was selected. Furthermore, the parameters including dew-point pressure, dew-point pressure, constant composition expansion $(\mathrm{P}-\mathrm{V}$ relation), and phase envelope were determined by phase equilibrium calculation of the hydrocarbon system. Meanwhile, the results of the theoretical calculation were verified with the measured results to confirm the accuracy of the simulation results.

\subsection{Phase Diagram Identification}

3.1.1. Fluid Properties of the Gas Reservoir. The methane content in the natural gas of the BZ19-6 condensate gas reservoir ranged from $70.85 \%$ to $78.25 \%$, with an average of $75.63 \%$. The nitrogen content was low, ranging from $0.12 \%$ to 
TABLE 1: Test data of the BZ19-6 condensate gas reservoir.

\begin{tabular}{|c|c|c|c|c|c|c|c|}
\hline Well & Strata & Depth (m) & Lithology & Gas layer thickness $(\mathrm{m})$ & Gas production $\left(\mathrm{m}^{3} / \mathrm{d}\right)$ & Oil production $\left(\mathrm{m}^{3} / \mathrm{d}\right)$ & $\operatorname{GOR}\left(\mathrm{m}^{3} / \mathrm{m}^{3}\right)$ \\
\hline \multirow{2}{*}{ BZ19-6-1 } & $\mathrm{E}_{1-2} k$ & $3566-4024$ & Glutenite & 242.8/12 layers & $8.1 \times 10^{4}$ & 73.24 & 1106 \\
\hline & Ar & $4024-4180$ & Gneiss & $96.8 / 12$ layers & $3.5 \times 10^{4}$ & 1.5 & l \\
\hline BZ19-6-2Sa & Ar & $3875-4466$ & Gneiss & 271/47 layers & $18.4 \times 10^{4}$ & 168 & 1381 \\
\hline BZ19-6-3 & $\mathrm{E}_{1-2} k$ & $3820-4248$ & Glutenite & $330.8 / 3$ layers & $1028-2032$ & l & 1539 \\
\hline BZ19-6-4 & Ar & $4400-4766$ & Gneiss & 220.1/20 layers & $31.2 \times 10^{4}$ & 305.16 & 1023 \\
\hline BZ19-6-5 & $\mathrm{E}_{1-2} k$ & $3483-4219$ & Glutenite & $228.7 / 6$ layers & $31.3 \times 10^{4}$ & 233.4 & 1413 \\
\hline
\end{tabular}

TABLE 2: Formation fluid data of the BZ19-6 condensate gas reservoir.

\begin{tabular}{|c|c|c|c|c|c|c|c|}
\hline Well & BZ19-6-1 & BZ19-6-2 & BZ19- & $-2 \mathrm{Sa}$ & $\begin{array}{c}\mathrm{BZ} 19- \\
6-3\end{array}$ & BZ19-6-4 & BZ19-6-5 \\
\hline Depth (m) & $\begin{array}{c}3566.8- \\
3634.0\end{array}$ & $\begin{array}{c}3873.7- \\
3923.5\end{array}$ & $\begin{array}{l}3879- \\
3998.7\end{array}$ & 4261.0 & 4079.1 & $\begin{array}{c}4411.0- \\
4499.8\end{array}$ & $\begin{array}{c}3500.0- \\
3566.0\end{array}$ \\
\hline Strata & $\mathrm{E}_{2} \mathrm{~s}_{3}$ & $\mathrm{Ar}$ & $\mathrm{Ar}$ & $\mathrm{Ar}$ & $\mathrm{E}_{2} \mathrm{k}_{1}$ & $\mathrm{Ar}$ & $\mathrm{E}_{2} \mathrm{k}_{1}$ \\
\hline $\mathrm{C}_{1}(\%)$ & 69.83 & 70.24 & 61.19 & 62.15 & 66.62 & 65.92 & 71.62 \\
\hline $\mathrm{C}_{2^{-}{ }_{6}}(\%)$ & 13.545 & 13.25 & 16.35 & 15.14 & 16.83 & 15.527 & 11.94 \\
\hline $\mathrm{C}_{7+}(\%)$ & 7.26 & 7.16 & 7.97 & 6.95 & 6.45 & 8.06 & 7.29 \\
\hline $\mathrm{CO}_{2}(\%)$ & 9.365 & 9.35 & 14.49 & 15.76 & 10.1 & 10.493 & 9.15 \\
\hline Relative density & 0.752 & 0.734 & 0.7424 & 0.8355 & 0.7931 & 0.7631 & 0.7515 \\
\hline Resin (\%) & 0.76 & 0.41 & 1.28 & 1.4 & 0.57 & 0.57 & 0.86 \\
\hline Asphaltene (\%) & 0.31 & 0.28 & 0.14 & 0.25 & 0.02 & 0.22 & 0.7 \\
\hline Wax (\%) & 13.95 & 15.04 & 13.84 & 17.79 & 7.32 & 18.25 & 9.7 \\
\hline Sulfur (\%) & 0.0201 & 0.0124 & 0.0148 & 0.0219 & 0.0116 & 0.0105 & 0.0191 \\
\hline $\mathrm{Pr} / \mathrm{Ph}$ & 1.29 & 1.38 & I & 1.39 & 1.51 & I & I \\
\hline Density at $20^{\circ} \mathrm{C}\left(\mathrm{g} / \mathrm{cm}^{3}\right)$ & 0.7945 & 0.7993 & 0.8089 & 0.8085 & 0.7866 & 0.7979 & 0.7914 \\
\hline Viscosity at $50^{\circ} \mathrm{C}(\mathrm{mPa} \cdot \mathrm{s})$ & 1.416 & 1.539 & 2.136 & 2.438 & 2.064 & 1.654 & 1.326 \\
\hline Density under formation conditions $\left(\mathrm{g} / \mathrm{cm}^{3}\right)$ & 0.4514 & l & 0.4678 & 0.4341 & 0.4224 & 0.4468 & 0.4172 \\
\hline Viscosity under formation conditions $(\mathrm{Pa} \cdot \mathrm{s}) \times 10^{-5}$ & 8.70 & I & 6.58 & 5.46 & 5.23 & 5.37 & 4.97 \\
\hline Formation temperature $\left({ }^{\circ} \mathrm{C}\right)$ & 134.1 & l & 152 & 152 & 156.9 & 171.9 & 138 \\
\hline Formation pressure $(\mathrm{MPa})$ & 45.71 & l & 46.93 & 48.86 & 48.64 & 48.72 & 45.9 \\
\hline $\begin{array}{l}\text { Difference between the formation pressure and dew-point } \\
\text { pressure }(\mathrm{MPa})\end{array}$ & 0.21 & l & 1.32 & 1.07 & 0.36 & l & 0 \\
\hline Critical pressure $(\mathrm{MPa})$ & 33.73 & l & 46.22 & 40.76 & 44.79 & l & 29.53 \\
\hline Critical temperature $\left({ }^{\circ} \mathrm{C}\right)$ & 24.1 & l & 64.7 & 52.44 & 49.7 & l & -22.2 \\
\hline Condensate content $\left(\mathrm{g} / \mathrm{m}^{3}\right)$ & 742.8 & l & 568.41 & 710.67 & 509.45 & I & 548.46 \\
\hline $\operatorname{GOR}\left(\mathrm{m}^{3} / \mathrm{m}^{3}\right)$ & 1106 & I & 1095 & 1438 & 1539 & 1023 & 1413 \\
\hline
\end{tabular}

$0.15 \%$. The $\mathrm{CO}_{2}$ content ranged from $9.35 \%$ to $15.76 \%$, with an average of $11.24 \%$ (Table 2 ). The average surface condensate density was $0.798 \mathrm{~g} / \mathrm{cm}^{3}$ (at $20^{\circ} \mathrm{C}$ ), the viscosity ranged from 1.326 to $2.438 \mathrm{mPa} \cdot \mathrm{s}$ (at $50^{\circ} \mathrm{C}$ ), with an average of $1.796 \mathrm{mPa} \cdot \mathrm{s}$, and the average contents of wax, sulfur, resin, and asphaltene were $13.7 \%, 0.016 \%, 0.836 \%$, and $0.274 \%$, respectively. The $\mathrm{Pr} / \mathrm{Ph}$ ratio is $1.29-1.51$, indicating a sedimentary environment of weak reduction and weak oxidation.

Formation fluids include gaseous hydrocarbons, liquid hydrocarbons, and nonhydrocarbons. The components of liquid hydrocarbons are particularly complex, usually considered as a whole $\left(\mathrm{C}_{7}{ }^{+}\right)$in PVT simulation $[27,28]$, and the critical temperature and critical pressure of the subsur- face multicomponent fluids can be further calculated [29, 30]. The previous PVT experimental results of the formation fluid indicate that the BZ19-6 structural fluid is a single-gas phase underground, with $\mathrm{C}_{1}+\mathrm{N}_{2}$ content ranging from $61.19 \%$ to $71.62 \%, \mathrm{C}_{2-6}+\mathrm{CO}_{2}$ content ranging from $21.09 \%$ to $30.90 \%$, and the $\mathrm{C}_{7+}$ content ranging from $6.45 \%$ to $8.06 \%$. It is a condensate gas reservoir in the triangle diagram of the fluid type of the oil and gas reservoir (Figure 2). The critical pressure of the formation fluid is low (29.53-46.22 $\mathrm{MPa}$ ), with an average of $39.00 \mathrm{MPa}$. The critical temperature is low (between $-22.20^{\circ} \mathrm{C}$ and $64.70^{\circ} \mathrm{C}$ ), with an average of $33.75^{\circ} \mathrm{C}$. However, the dew-point pressure was high $(45.50-$ 48.28 $\mathrm{MPa}$ ) and the dew-point pressure difference was small 


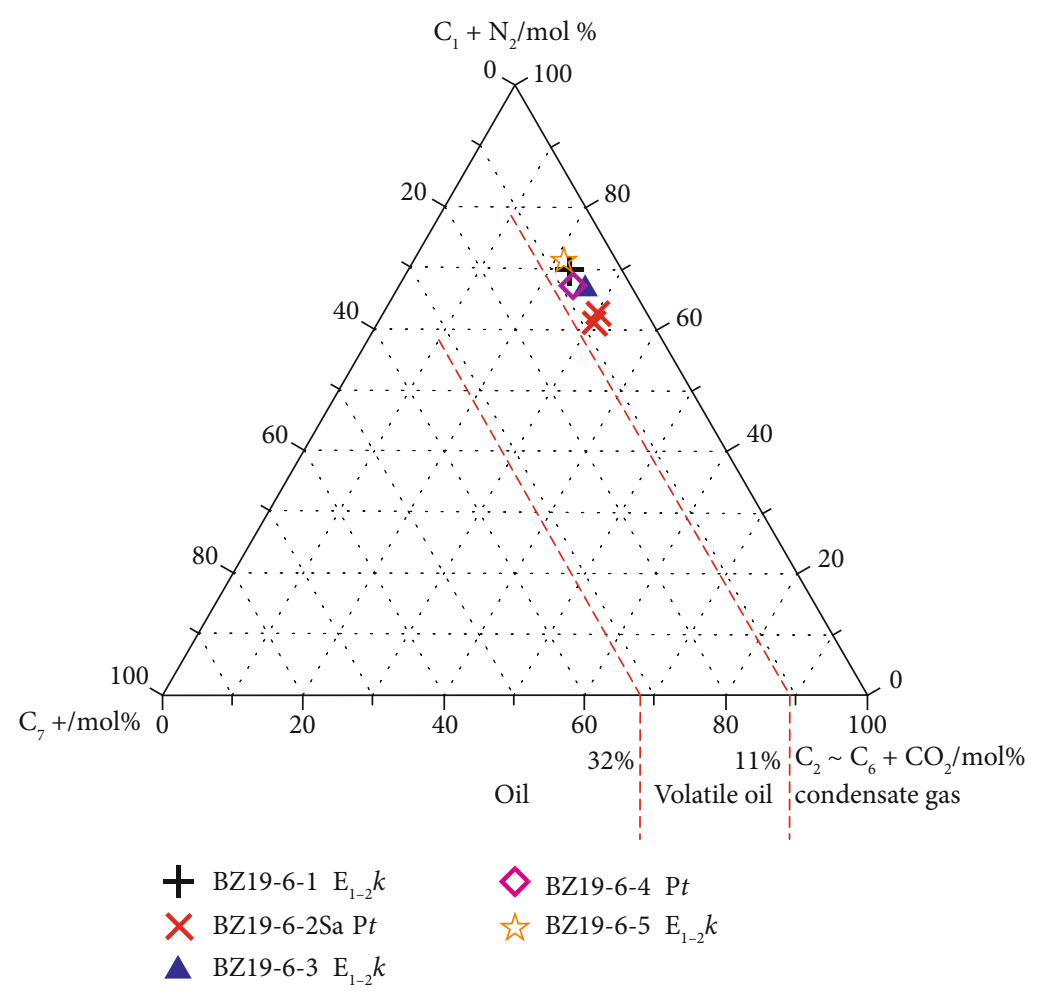

Figure 2: Fluid type identification of the BZ19-6 gas reservoir according to the three-component diagram $\left(\mathrm{C}_{1}+\mathrm{N}_{2}, \mathrm{C}_{2} \sim \mathrm{C}_{6}+\mathrm{CO}_{2}\right.$, and $\left.\mathrm{C}_{7+}\right)$. The result indicates that BZ19-6 belongs to condensate gas reservoir.

(0.21-1.32 MPa), indicating that the heavy hydrocarbon content in the formation fluid was high. The average critical condensate pressure was $47.32 \mathrm{MPa}$, the average critical condensate temperature was $402.10^{\circ} \mathrm{C}$, and the formation temperature was between the critical temperature and critical condensate temperature. In the constant volume depletion experiment, the maximum amount of retrograde condensate reached $40.97 \%$ and the average surface condensate content was $615.96 \mathrm{~g} / \mathrm{m}^{3}$, which is indicates a gas reservoir with extremely high condensate content.

3.1.2. Characteristics of the Phase Diagram. Several PVT experimental samples were supplemented from the Kongdian Fm. to verify the accuracy of the previous experimental results and Archean gas reservoir in the BZ19-6 structure. The P-T phase diagram is shown in Figure 3. The formation temperature isoline was in the critical condensate temperature range, and the dew-point pressure was lower than the formation pressure; the hydrocarbon fluid existed in a single-gas phase.

The difference between the formation pressure and dewpoint pressure was 1.15 MPa in well BZ19-6-2Sa; the critical pressure was $46.22 \mathrm{MPa}$, critical temperature was $64.70^{\circ} \mathrm{C}$, critical condensate pressure was $48.19 \mathrm{MPa}$, and critical condensate temperature was $393.40^{\circ} \mathrm{C}$. In the constant volume depletion test, the maximum reverse condensate pressure was $27.62 \mathrm{MPa}$, maximum amount of condensate was $26.79 \%$, production GOR was $1381\left(\mathrm{~m}^{3} / \mathrm{m}^{3}\right)$, and condensate content in the ground was $568.41 \mathrm{~g} / \mathrm{m}^{3}$ (Figure 3(a)). The difference between the formation pressure and the dew-point pressure was 2.92 MPa in well BZ19-6-5; the critical pressure was $43.08 \mathrm{MPa}$, critical temperature was $-9.90^{\circ} \mathrm{C}$, critical condensate pressure was $48.19 \mathrm{MPa}$, and critical condensate temperature was $364.30^{\circ} \mathrm{C}$. In the constant volume depletion test, the maximum reverse condensate pressure was determined to be $19.00 \mathrm{MPa}$; the maximum amount of condensate was $19.74 \%$, production GOR was $1421\left(\mathrm{~m}^{3} / \mathrm{m}^{3}\right)$, and condensate content on the ground was $594.31 \mathrm{~g} / \mathrm{m}^{3}$ (Figure 3(b)). The BZ19-6 condensate gas reservoir exhibits a small ground surface pressure difference and high condensate oil content.

3.2. Empirical Statistical Identification. Several empirical statistical discrimination methods of phase behavior types have been proposed using statistics based on physical property data, such as fluid composition, average molecular weight, density, and gas-oil ratio, which reflect the phase behavior types of oil and gas reservoirs [31]. In this study, five reliable empirical discriminant methods such as the block diagram method, average relative molecular weight, $\varphi_{1}$ parameter method, rank number method, and $Z$-factor method were used to comprehensively identify the phase behaviors of hydrocarbon fluids in the BZ19-6 structure.

3.2.1. Four-Parameter Block Diagram Method. The parameters and criteria used in the four-parameter block diagram method are presented in Ref. [30]. The parameters of the Kongdian Fm. and Archean buried hill is primarily distributed in the lower-left corner of the box of the oil ring gas 


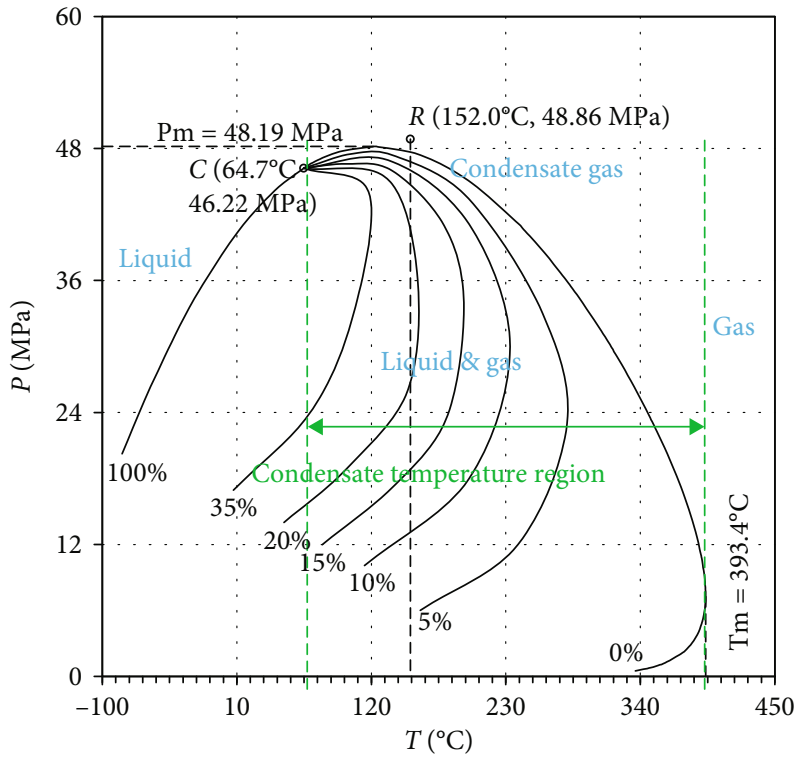

(a) BZ19-6-2Sa Pt

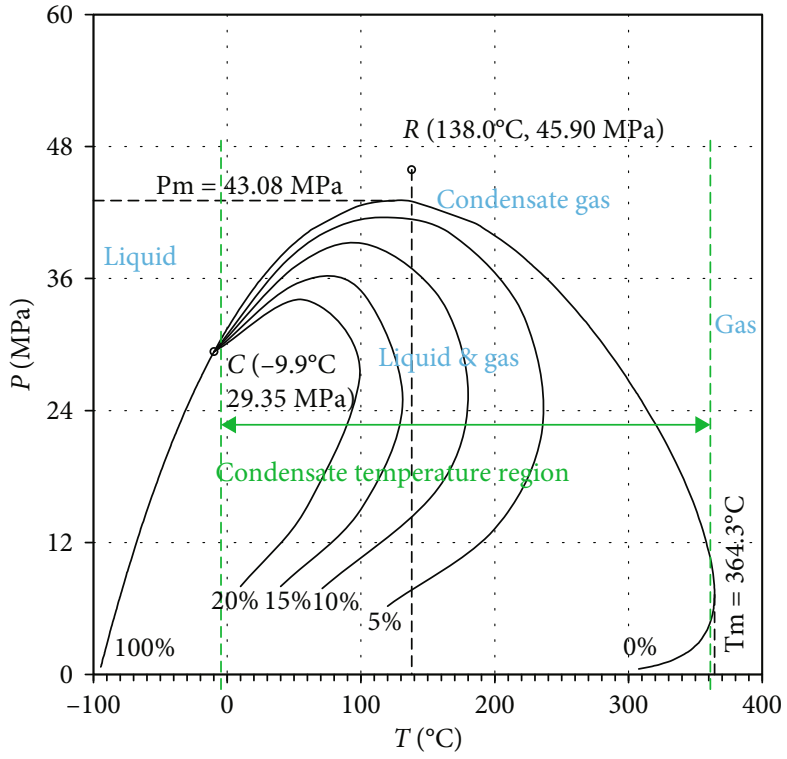

(b) BZ19-6-5 $\mathrm{E}_{1-2} \mathrm{k}$

FIGURE 3: Phase diagram of formation fluid in BZ19-6 structure in (a) well BZ19-6-2Sa, $4261 \mathrm{~m}, \mathrm{Pt}$ sample in the well and (b) well BZ19-6-5, 3500.00-3566.00 $\mathrm{m}, \mathrm{E}_{1-2} \mathrm{k}$ sample in the well.

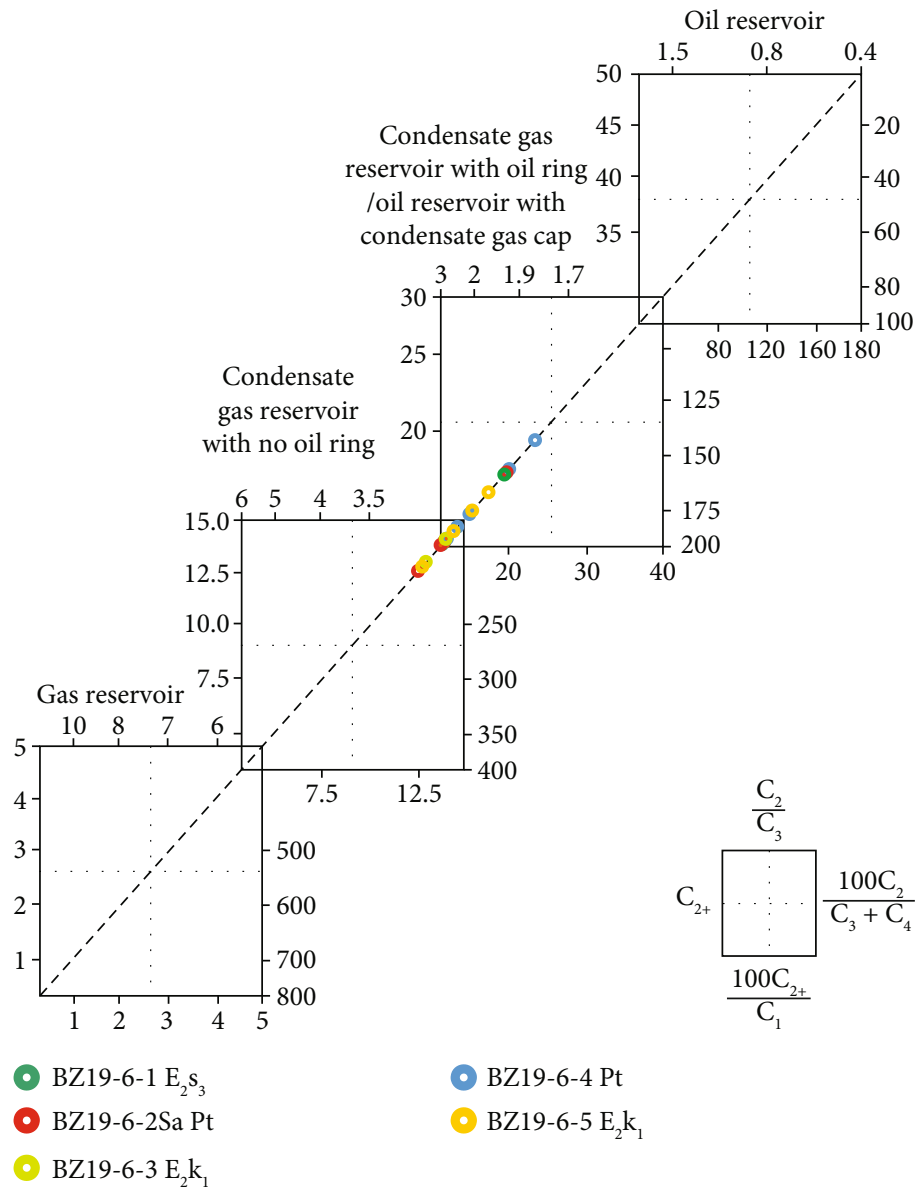

Figure 4: Four-parameter block diagram and the types of condensate gas reservoir in the BZ19-6 structure. The four parameters are $\mathrm{C}_{2+}$, $\mathrm{C}_{2} / \mathrm{C}_{3}, 100 \mathrm{C}_{2} /\left(\mathrm{C}_{3}+\mathrm{C}_{4}\right)$, and $100 \mathrm{C}_{2+} / \mathrm{C}_{1}$, respectively. Types of condensate gas reservoir are both in boxes of gas reservoir with oil rings or condensate gas cap reservoir, and condensate gas reservoir without oil rings. 


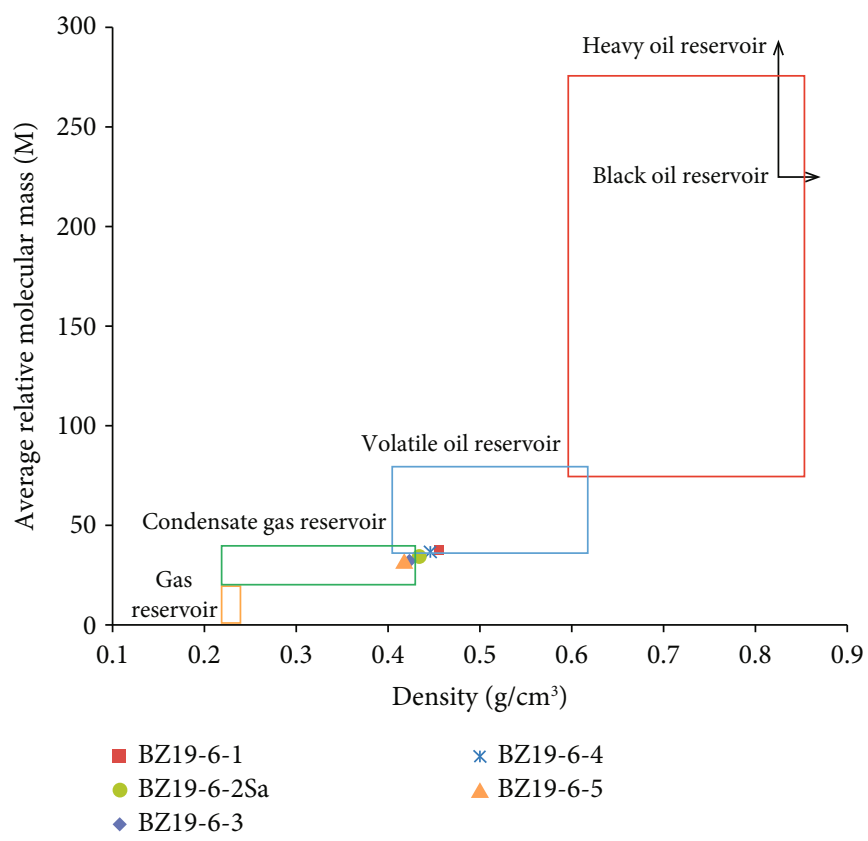

FIGURE 5: Identification map of phase behavior identification in BZ19-6 gas reservoir according to the formation fluid density and average relative molecular mass. The results indicate a phase behavior similar to that of condensate gas and volatile oil reservoirs.

TABLE 3: Phase behavior identification of oil and gas reservoir in the BZ19-6 structure by empirical statistics method.

\begin{tabular}{|c|c|c|c|c|c|c|c|c|c|}
\hline Well & Strata & Depth (m) & $\mathrm{C}_{5+}(\%)$ & $\mathrm{C}_{1} / \mathrm{C}_{5+}$ & $\varphi_{1}$ parameter & $\begin{array}{c}\text { Rank } \\
\text { number }\end{array}$ & $Z$-factor & $\begin{array}{c}\text { Average } \\
\text { molecular mass }\end{array}$ & Phase behavior \\
\hline BZ19-6-1 & $\mathrm{E}_{2} \mathrm{~s}_{3}$ & $3566.8-3634$ & 8.4 & 8.31 & $\varphi_{1}=12.74$ & $\Phi=14$ & $\begin{array}{l}Z_{1}=5.38 \\
Z_{2}=5.13\end{array}$ & $M=37.28$ & $\begin{array}{l}\text { Condensate gas reservoir } \\
\text { with oil rings }\end{array}$ \\
\hline \multirow{2}{*}{ BZ19-6-2Sa } & \multirow{2}{*}{$\mathrm{Pt}$} & 4261 & 7.35 & 8.45 & $\varphi_{1}=11.81$ & $\Phi=14$ & $\begin{array}{l}Z_{1}=5.26 \\
Z_{2}=5.04\end{array}$ & $M=39.97$ & $\begin{array}{l}\text { Condensate gas reservoir } \\
\text { with oil rings }\end{array}$ \\
\hline & & $3879-3998.7$ & 8.47 & 7.22 & $\varphi_{1}=13.58$ & $\Phi=14$ & $\begin{array}{l}Z_{1}=5.15 \\
Z_{2}=4.91\end{array}$ & $M=34.89$ & $\begin{array}{c}\text { Condensate gas reservoir } \\
\text { with oil rings }\end{array}$ \\
\hline BZ19-6-3 & $\mathrm{E}_{2} \mathrm{k}_{1}$ & 4079.1 & 6.81 & 9.78 & $\varphi_{1}=14.91$ & $\Phi=13$ & $\begin{array}{l}Z_{1}=5.58 \\
Z_{2}=5.37\end{array}$ & $M=32.97$ & $\begin{array}{l}\text { Condensate gas reservoir } \\
\text { with oil rings }\end{array}$ \\
\hline BZ19-6-4 & $\mathrm{Pt}$ & $4411-4499.8$ & 8.68 & 7.59 & $\varphi_{1}=12.37$ & $\Phi=14$ & $\begin{array}{l}Z_{1}=5.34 \\
Z_{2}=5.10\end{array}$ & $M=36.56$ & $\begin{array}{l}\text { Condensate gas reservoir } \\
\text { with oil rings }\end{array}$ \\
\hline BZ19-6-5 & $\mathrm{E}_{2} \mathrm{k}_{1}$ & $3500-3566$ & 7.98 & 8.97 & $\varphi_{1}=13.12$ & $\Phi=14$ & $\begin{array}{l}Z_{1}=5.38 \\
Z_{2}=5.15\end{array}$ & $M=32.25$ & $\begin{array}{l}\text { Condensate gas reservoir } \\
\text { with oil rings }\end{array}$ \\
\hline
\end{tabular}

reservoir or condensate gas cap reservoir and the upper-right corner of the box of the condensate gas reservoir without oil rings, indicating that the reservoir fluid type belongs to the gas reservoir with oil rings (Figure 4).

3.2.2. Identification of Formation Fluid Density and Average Relative Molecular Mass. The density of the formation fluid is directly measured by sampling; it can also be obtained by an empirical formula, in case measured data are unavailable. The average relative molecular mass and discriminant criteria are shown in "Technical requirements for determining phase behaviors of gas condensate reservoirs" (SY/T 61012012) [32]. The average molecular mass of the reservoir fluid in the Kongdian Fm. and the Archean buried hill in the BZ19-6 structure is 32.25-39.97; the density of the formation fluid is $0.417-0.468 \mathrm{~g} / \mathrm{cm}^{3}$ (Figure 5), which is between those of the condensate gas reservoir and volatile oil reservoir. However, the reservoir is speculated to be a condensate gas reservoir with oil rings.

3.2.3. $\varphi_{1}$ Parameter, Rank Number, and Z-Factor Method. Considering the $\mathrm{C}_{5+}$ content criterion, $\mathrm{C}_{1} / \mathrm{C}_{5+}$ ratio, $\varphi_{1}$ parameter, rank number, and $Z$-factor methods, the fluid phase behavior of the Kongdian Fm. and the Archean buried hill reservoir in the BZ19-6 structure was analyzed, and the oil ring characteristics were determined. Various empirical statistical discrimination methods and standards were presented in Ref. 32. The results are shown in Table 3. The results of all the methods show that BZ19-6 is a condensate gas reservoir with oil rings. 


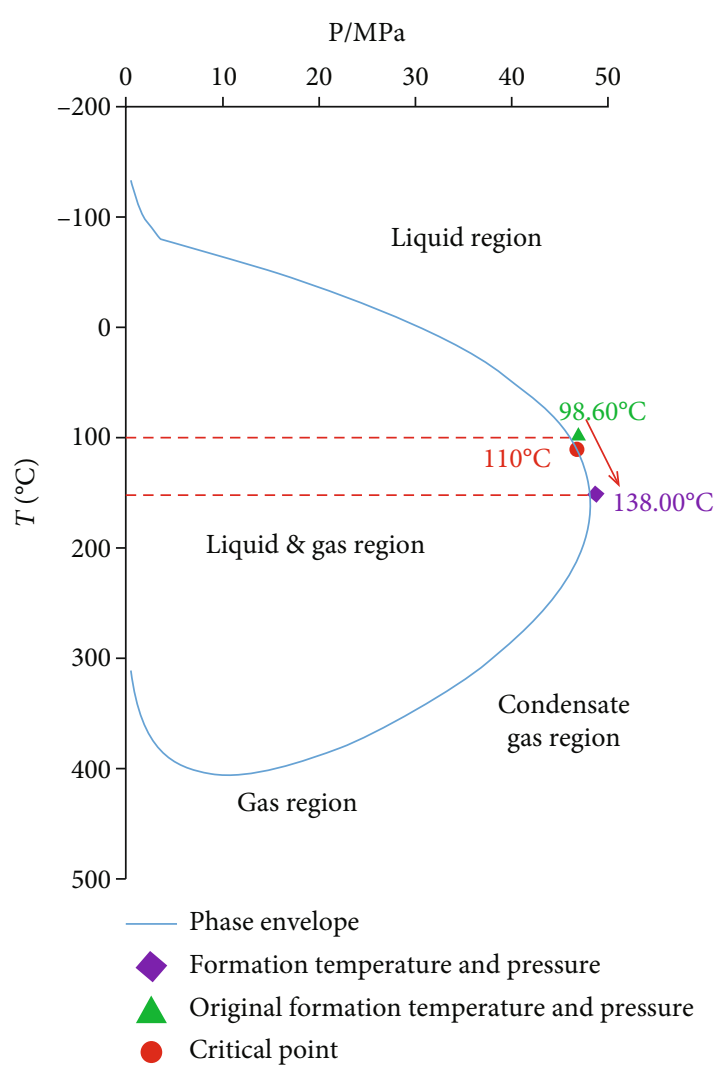

FIGURE 6: Schematic diagram of retrograde evaporation in BZ19-6 gas reservoirs. The original formation temperature $\left(98.6^{\circ} \mathrm{C}\right)$ was less than the critical temperature $\left(110^{\circ} \mathrm{C}\right)$, fluid existed in a singleliquid phase, following the increase of burial depth, and the formation temperature $\left(138^{\circ} \mathrm{C}\right)$ exceeds the critical temperature, thus forming retrograde evaporation.

3.3. Properties of Underground Fluid. The density of the underground fluid ranged from 0.4172 to $0.4678 \mathrm{~g} / \mathrm{cm}^{3}$, with an average of $0.44 \mathrm{~g} / \mathrm{cm}^{3}$, and an average viscosity of 6.05 $\times 10^{-5} \mathrm{mPa} \cdot \mathrm{s}$; the formation temperature and pressure are higher than the critical temperature and pressure of the hydrocarbon fluid, which may be a supercritical fluid. This fluid exists above the critical temperature and critical pressure and exhibits unique physical properties. Its density and solubility are close to those of liquid and are sensitive to temperature and pressure changes. Its diffusion coefficient is close to that of gas and has an extraordinary ability to extract organic matter. There is no obvious gas and liquid interface, and the event phase effect is not obvious or does not exist [33]. These special properties are conducive to effective hydrocarbon migration and accumulation.

\section{Discussion on Formation Mechanism of Condensate Gas Reservoirs}

Condensate gas reservoirs of different genetic types in hydrocarbon-rich sags significantly differ in terms of fluid properties, phase characteristics, geochemical characteristics, and distribution rules, which can be used to distinguish condensate gas reservoirs of different genetic types. The study of natural gas and condensate oil in the condensate oil-gas sys- tem is crucial to understand the genetic mechanisms of condensate gas reservoirs.

Some studies have shown that natural gas in the BZ19-6 Archean group buried hills and the overlying Paleogene Kongdian Fm. is an oil-type gas with the characteristics of different mature natural gas mixtures. There are three suites of hydrocarbon source rocks for deep oil and gas, among which the infilling from the third member of the Shahejie $\mathrm{Fm}$. is the primary source. The formation of deep condensate gas reservoirs is characterized by oil-gas charging and oiltype gas formation in different periods, which have experienced early reservoir formation and destruction (from 24 $\mathrm{Ma}$ to $5 \mathrm{Ma} \mathrm{BP}$ ), late reservoir adjustment, and condensate gas reservoir conversion (from $5 \mathrm{Ma} \mathrm{BP}$ ) [8].

\subsection{Genesis of the BZ19-6 Condensate Gas Reservoir}

4.1.1. Retrograde Evaporation. Retrograde evaporation is a notable characteristic of condensate gas reservoirs. As the temperature and pressure increases with burial depth, the liquid hydrocarbons in the oil and gas reservoirs gradually dissolve and evaporate, forming a condensate gas reservoir of inverse evaporation origin, with oil rings or condensate gas cap.

The burial history of BZ19-6-1 shows that the burial depth from the lower member of the Minghuazhen Fm. (5 Ma BP) increased substantially by approximately $1100 \mathrm{~m}$, during the major accumulation period. The geothermal gradient in this area is approximately $3.40^{\circ} \mathrm{C} / 100 \mathrm{~m}$, thereby increasing the formation temperature by approximately $37.40^{\circ} \mathrm{C}$ during the hydrocarbon accumulation period.

The rise in the formation temperature and pressure leads to the gradual dissolution and evaporation of liquid hydrocarbon in the reservoir containing the gaseous hydrocarbon, that is, retrograde evaporation. The BZ19-6 oil and gas reservoirs were identified as a condensate gas reservoir with oil rings, which is consistent with the phase characteristics of the retrograde evaporation of genetic condensate gas reservoir. This implies that the BZ19-6 condensate gas reservoir experienced retrograde evaporation. The formation process is presented in Figure 6. The original formation temperature was less than the critical temperature; the hydrocarbon fluid existed in a single-liquid phase, and the formation temperature exceeded the critical temperature with increased burial depth. The above indicators support that the isothermal depressurization line moves downward, and the hydrocarbon fluid changes from the liquid phase to the condensate gas phase, forming a retrograde evaporation genetic condensate gas reservoir.

4.1.2. Gas Invasion. Significant increase of the burial depth of the BZ19-6 structure since the Neogene resulted in the rapid increase in the maturity of the source rocks in the Bozhong Sag with the generation of a large amount of gas. The deep natural gas was charged into the early oil reservoirs along the unconformity and deep faults, forming gas invasion condensate gas reservoirs. The evidence of gas invasion in the BZ19-6 structure is as follows. 
TABLE 4: Carbon isotope data of natural gas of the BZ19-6 and BZ21-22 structures.

\begin{tabular}{|c|c|c|c|c|c|c|c|c|c|}
\hline \multirow{2}{*}{ Well } & \multirow{2}{*}{ Strata } & \multirow{2}{*}{ Depth $(\mathrm{m})$} & \multicolumn{5}{|c|}{$\delta^{13} \mathrm{C}(\%)$} & \multicolumn{2}{|c|}{$R_{\mathrm{o}}(\%)$} \\
\hline & & & $\delta^{13} \mathrm{C}_{1}$ & $\delta^{13} \mathrm{C}_{2}$ & $\delta^{13} \mathrm{C}_{3}$ & $\delta^{13} \mathrm{C}_{1}-\delta^{13} \mathrm{C}_{2}$ & $\delta^{13} \mathrm{CO}_{2}$ & By Pedersen et al. [27] & By Manafi et al. [28] \\
\hline BZ19-6-1 & $\mathrm{Ar}$ & $4043.4-4142$ & -38.8 & -27.0 & -25.6 & -11.8 & -3.6 & 1.64 & 1.61 \\
\hline BZ19-6-1 & $\mathrm{E}_{1-2} \mathrm{k}$ & $3566.8-3634$ & -38.5 & -27.0 & -25.5 & -11.5 & -7 & 1.71 & 1.66 \\
\hline BZ19-6-2Sa & $\mathrm{Ar}$ & $3879-3998.7$ & -38.64 & -26.61 & -24.40 & -12.03 & I & 1.68 & 1.64 \\
\hline BZ19-6-2 & $\mathrm{Ar}$ & $3874-3923.5$ & -38.66 & -25.77 & -24.60 & -12.89 & I & 1.68 & 1.64 \\
\hline BZ19-6-3 & $\mathrm{Ar}$ & 4079.19 & -37.97 & -25.42 & -24.70 & -12.54 & I & 1.85 & 1.76 \\
\hline BZ21-2-1 & $\mathrm{Pz}$ & $4685.37-5141$ & -38.80 & -27.60 & -21.50 & -11.2 & I & 1.64 & 1.61 \\
\hline BZ22-1-2 & $\mathrm{O}$ & $4354-4611$ & -35.30 & -22.90 & -22.70 & -12.4 & l & 2.73 & 2.34 \\
\hline BZ22-1-2 & $\mathrm{O}$ & 5003.19 & -37.50 & -27.60 & -21.50 & -9.9 & I & 1.98 & 1.85 \\
\hline BZ22-2-1ST & $\mathrm{Mz}$ & $4185.5-4348.5$ & -37.30 & -25.10 & -25.50 & -12.2 & I & 2.04 & 1.89 \\
\hline
\end{tabular}

TABLE 5: Heavy hydrocarbon gases data of the BZ19-6 gas reservoirs.

\begin{tabular}{lcccccccc}
\hline Well & Strata & Depth $(\mathrm{m})$ & $\mathrm{A}$ & $\mathrm{B}$ & $\mathrm{D}$ & $\mathrm{E}$ & $\mathrm{F}$ & $\mathrm{G}$ \\
\hline BZ19-6-1 & $\mathrm{Ar}$ & $4043.4-4142$ & 30.85 & 162.07 & 1.59 & 3.58 & 5.25 & 0.13 \\
BZ19-6-1 & $\mathrm{E}_{1-2} \mathrm{k}$ & $3566.8-3634$ & 35.00 & 47.00 & 1.55 & 1.92 & 1.34 & 0.42 \\
\hline
\end{tabular}

A: cyclohexane/benzene; B: n-hexane/benzene; C: n-heptane/methylcyclohexane; D: n-hexane/methylcyclopentane; E: n-hexane/cyclohexane; F: toluene/methylcyclohexane.

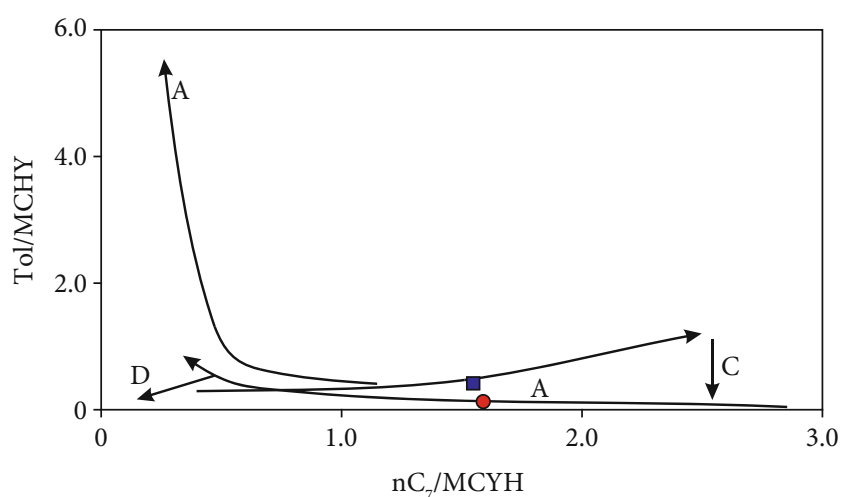
A Evaporative fractionation
D Biodegradation
B Maturation
口 Ar
C Extraction of aromatics
- $\mathrm{E}_{1-2} \mathrm{k}$

FIgURE 7: Cross-plot of paraffinicity versus aromaticity of the heavy hydrocarbon gases in BZ19-6 gas reservoirs (after [37]).

(1) Physical Properties of Condensate Oil and Gas. The isomerization ratios of $\mathrm{C}_{29}$ sterane, $20 \mathrm{~S} /(20 \mathrm{~S}+20 \mathrm{R})-24$-ethyl- $\alpha \alpha \alpha$ cholestane $\left(\mathrm{C}_{29} 20 \mathrm{~S} /[20 \mathrm{~S}+20 \mathrm{R}]\right)$ and $\beta \beta /(\beta \beta+\alpha \alpha)$-24-ethylcholestane $\left(\mathrm{C}_{29} \beta \beta /[\beta \beta+\alpha \alpha]\right)$ of the condensate oils were $0.38-0.56$, and $0.47-0.69$, respectively, indicating that the majority of condensate oils were thermally mature [25]. The carbon isotope values of the condensate gas of methane, ethane, and propane are between $-37.97 \%$ and $-38.80 \%$, $-25.42 \%$ and $-27.00 \%$, and $-24.40 \%$ ond $-25.60 \%$, respectively. As the deep natural gas BZ19-6 is a typical thermal gas, the maturity of the natural gas can be calculated by the $\delta^{13} \mathrm{C}_{1}-R_{\mathrm{o}}$ empirical formula proposed by Dai et al. [34, 35]. The $R_{\mathrm{o}}$ values calculated using the two formulas ranged from $1.61 \%$ to $1.85 \%$ (Table 4 ). The values of $\delta^{13} \mathrm{C}_{2}-\delta^{13} \mathrm{C}_{1}$ are also an effective index for measuring the maturity of natural gas, which decreases with maturity [36]. The values of $\delta^{13} \mathrm{C}_{2}-\delta^{13} \mathrm{C}_{1}$ of the gas in the BZ19-6 structure lie between $11.50 \%$ and $12.89 \%$, and the corresponding $R_{\mathrm{o}}$ is approximately $1.5 \%$, indicating a primary gas stage. This indicates that the natural gas of the BZ19-6 structure is the product of the deep-source rock in the Bozhong Sag formed during the high-maturity stage.

The heavy hydrocarbon gas of the BZ19-6 structure is poor in light aromatics (benzene and toluene) and rich in cycloalkanes (methylcyclopentane, cyclohexane, and methylcyclohexane) (Table 5). This feature may be related to evaporative fractionation in the process of gas invasion [37], which belongs to the product of the initial stage of evaporative fractionation according to Thompson's cross-plot (Figure 7). However, Thompson's cross-plot is ineffective in validating the formation of a condensate gas by evaporation fractionation. However, regardless of the influence of organic matter type and maturity, the presence of an unusually high or abnormally low content of low-carbon aromatic hydrocarbons in the crude oil or condensate gas, could potentially indicate whether the crude oil or condensate gas experienced a secondary alteration and whether evaporation fractionation was the reason [38]. The late charging of the natural gas transforms the early oil reservoirs into condensate gas reservoirs and increases the wax content of condensate oil and paraffinicity of the heavy hydrocarbon gas, ensuring that the oil quality is higher than that of the normal condensate [13]. The average condensate density of the BZ19-6 structure is $0.798 \mathrm{~g} / \mathrm{cm}^{3}$ (at $20^{\circ} \mathrm{C}$ ), which is higher than the normal condensate density (approximately $0.74 \mathrm{~g} / \mathrm{cm}^{3}$ ); the wax content and the paraffinicity is high, with an average of 


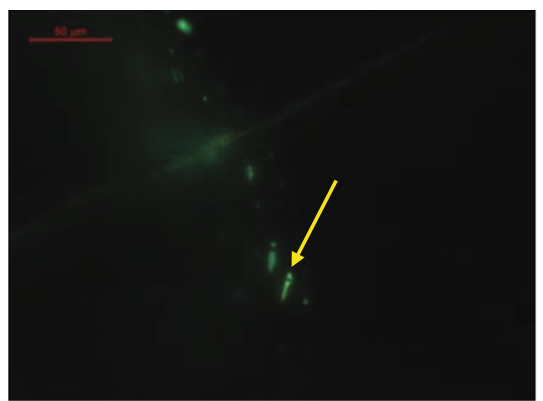

(a)

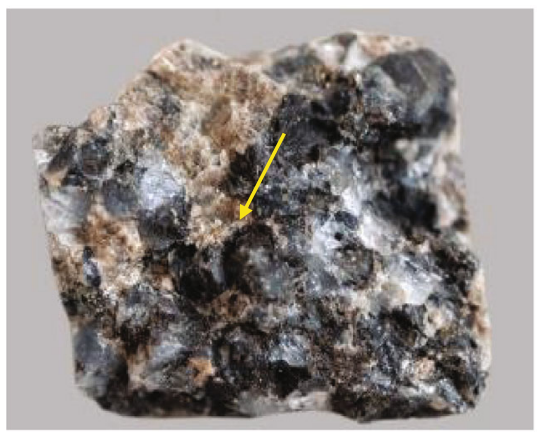

(d)

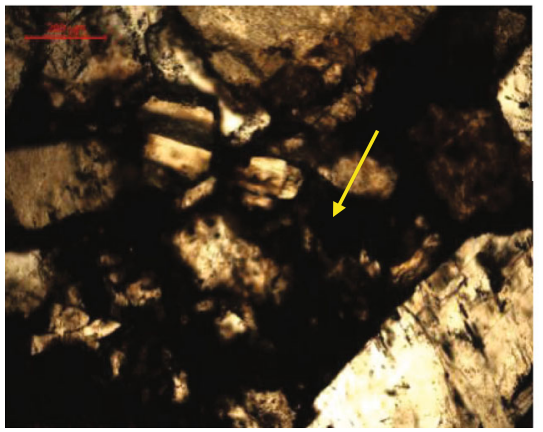

(g)

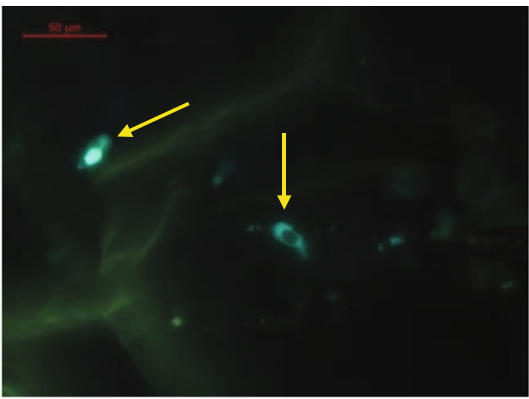

(b)

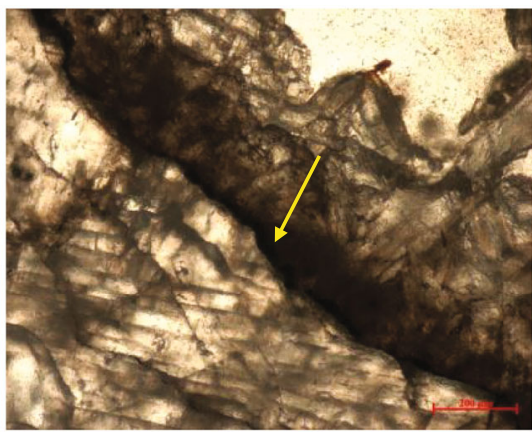

(e1)

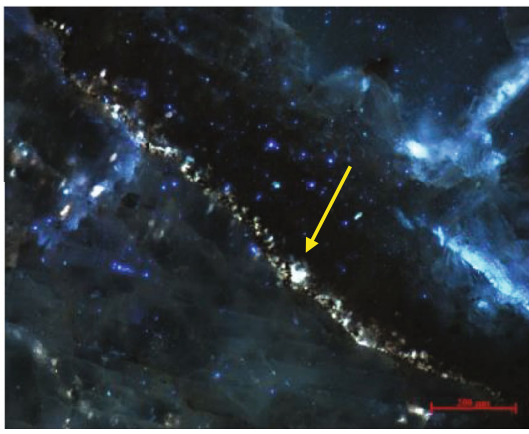

(e2)

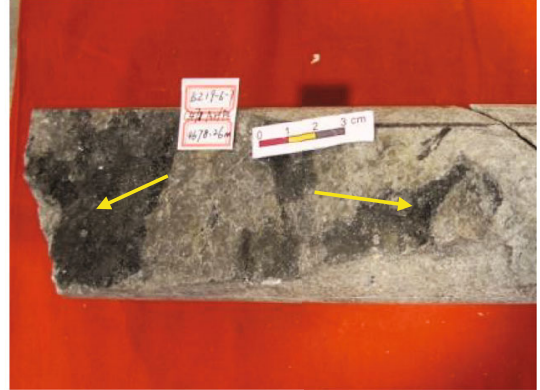

(c)

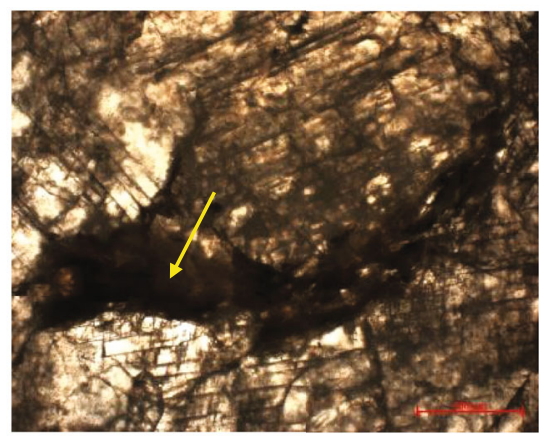

(f1)

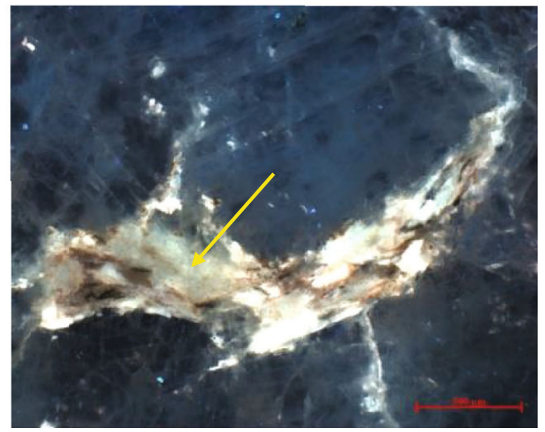

(f2)

FIGURE 8: Characteristics of the fluid inclusions and asphalt of the BZ19-6 structure. (a) $\mathrm{E}_{1-2} \mathrm{k}, 3735.00 \mathrm{~m}$, showing fluorescence, yellow-green fluorescence oil, and gas inclusions with low maturity. (b) $\mathrm{E}_{1-2} \mathrm{k}, 3735.00 \mathrm{~m}$, showing fluorescence, blue-white light oil and gas inclusions with high maturity. (c) Pt, $4678.80 \mathrm{~m}$, showing dark brown solid asphalt in the fractures. (d) $\mathrm{E}_{1-2} \mathrm{k}, 3610.00 \mathrm{~m}$, showing dark brown solid asphalt in the pores. (e1, e2, f1, and f2) Pt, $4678.80 \mathrm{~m}$, showing plane-polarized light and fluorescence; the dark brown solid asphalt in the fractures show yellow-white fluorescence. $(\mathrm{g}) \mathrm{E}_{2} \mathrm{~s}_{3}{ }^{\mathrm{L}}$, showing dark brown solid asphalt in the intergranular pores.

13.7\% and 1.57 (Tables 2 and 5), respectively. This observation confirms that the BZ19-6 reservoirs have experienced gas invasion.

(2) Characteristics of Fluid Inclusions and Asphalt in Reservoirs. Oil inclusions in the BZ19-6 condensate gas reservoir are widely developed with GOI values of up to $80 \%$. Observation under a microscope revealed that the low-mature light oil inclusions primarily exhibited a yellow-green fluorescence color (Figure 8(a)), and the highly mature gas-rich inclusions in the deep reservoirs $\left(\mathrm{E}_{1-2} \mathrm{k}\right.$ and $\left.\mathrm{Pt}\right)$ exhibited a blue-white color (Figure $8(\mathrm{~b})$ ). The abundance of gas inclusions in the deep layer is higher than that in the shallow layer, which is also an evidence of gas invasion.

Dark brown solid asphalt can be observed in the fractures and pores of the upper reservoir of the BZ19-6 structure
(Figures 8(c) and 8(d)) and is also visible under the microscope (Figures $8(\mathrm{e} 1), 8(\mathrm{fl})$, and $8(\mathrm{~g})$ ); it displays a green color under ultraviolet (UV) excitation fluorescence (Figures 8(e2) and 8(f2)), which demonstrates the characteristics of oil asphalt. The equivalent vitrinite reflectance of the asphalt is only $0.9 \%$, which indicates a gas invasion origin for the asphalt [8].

The late gas invasion leads to an increase in the light component (mainly $\mathrm{CH}_{4}$ ) and the phase behavior of the oil and gas changes accordingly. PVTsim20 software was used to reconstruct the fluid components of the BZ19-6 reservoir and analyze the influence of a single factor on the fluid phase by controlling the variables. The changes in the oil and gas phase behavior during the gas invasion were simulated by increasing the $\mathrm{CH}_{4}$ content in the hydrocarbon system, and the results are shown in Figure 9. With an increase in the $\mathrm{CH}_{4}$ content (gas invasion intensity), the critical temperature 


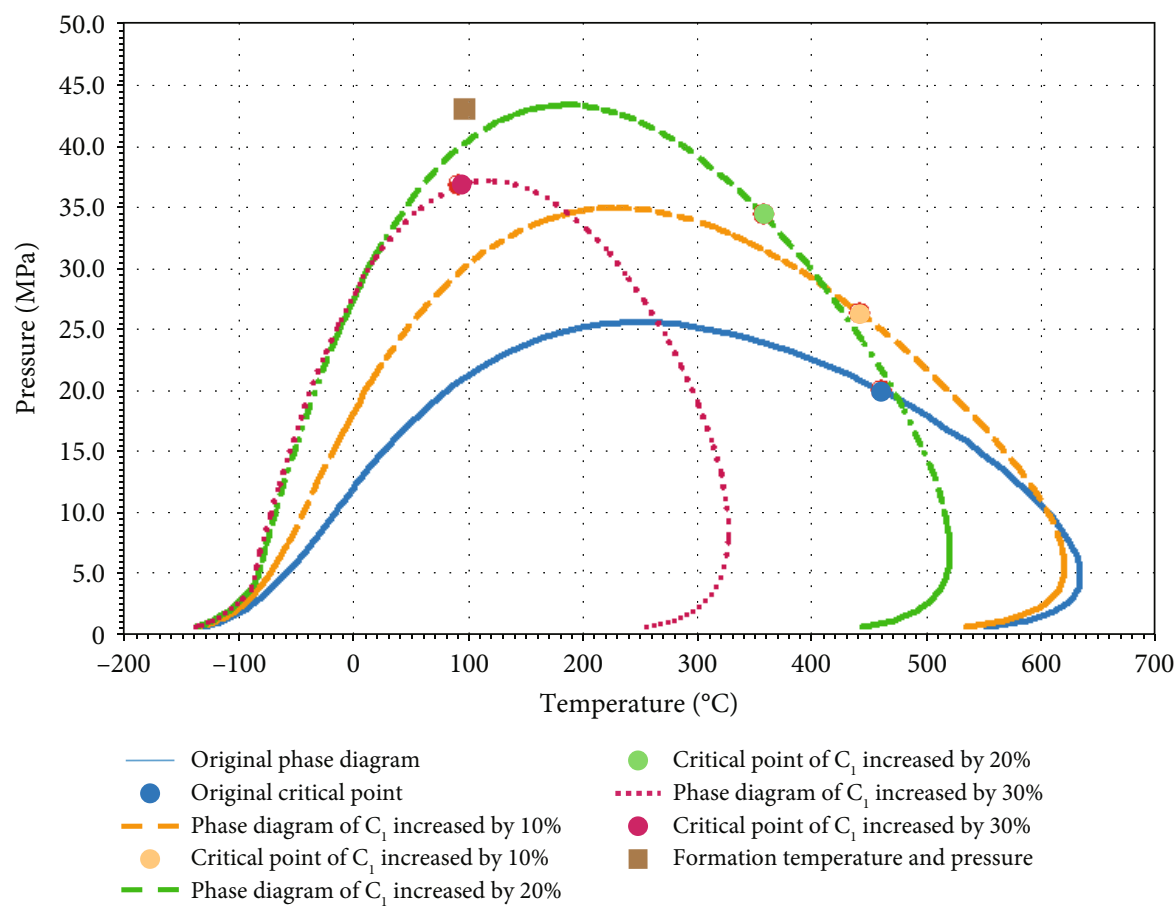

FIGURE 9: Schematic showing oil and gas phase behavior changes with the increase of gas invasion. With an increase in the $\mathrm{CH}_{4}$ content, the critical temperature and critical pressure increased, and the critical point shifted from right to left. When the $\mathrm{CH}_{4} \mathrm{content}$ increased by $10 \%$, $20 \%$, and $30 \%$, the critical temperature decreased from $461.50^{\circ} \mathrm{C}$ to $443.00^{\circ} \mathrm{C}, 356.80^{\circ} \mathrm{C}$, and $93.10^{\circ} \mathrm{C}$, respectively.

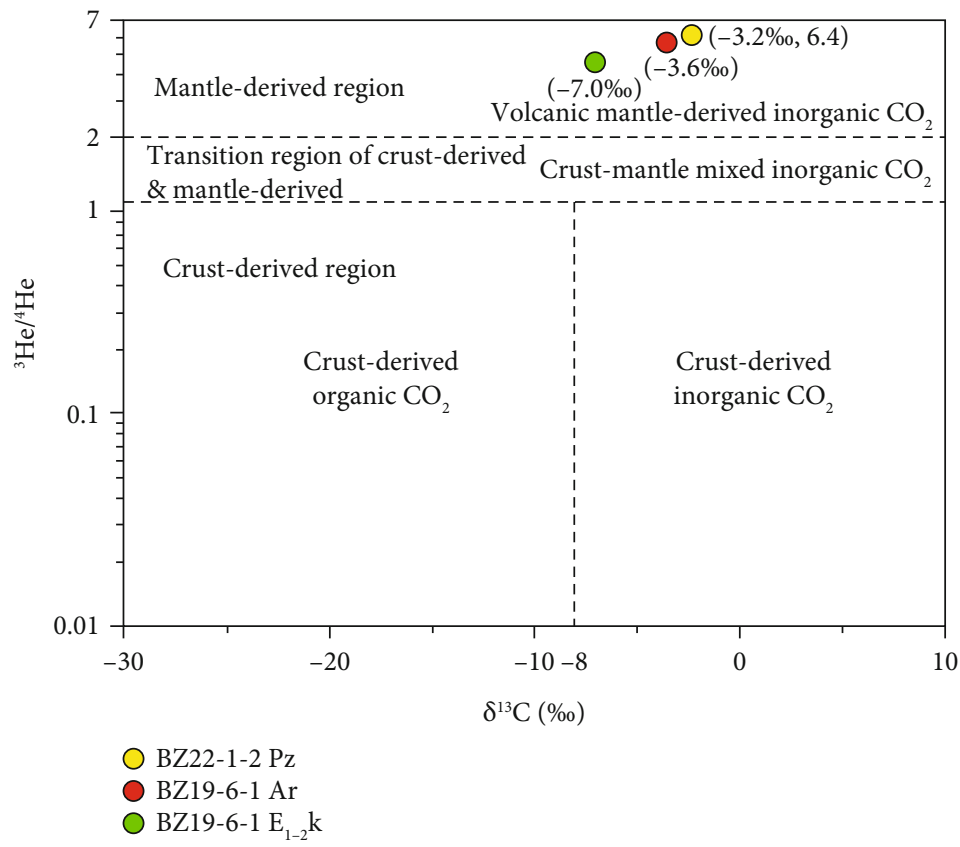

Figure 10: $\mathrm{CO}_{2}$ genesis discrimination chart in the BZ19-6 structure (after [39]). According to ${ }^{3} \mathrm{He} /{ }^{4} \mathrm{He}$ and $\delta^{13} \mathrm{C}_{\mathrm{CO} 2}$ data and genetic partition, $\mathrm{CO}_{2}$ in the BZ19-6 structure belongs to mantle-derived gas.

and critical pressure increased, and the critical point shifted from right to left. When the $\mathrm{CH}_{4}$ content increased by $10 \%$, the critical temperature decreased from $461.5^{\circ} \mathrm{C}$ to $443.0^{\circ} \mathrm{C}$. When the $\mathrm{CH}_{4}$ content increased by $20 \%$, the critical temper- ature decreased from $461.50^{\circ} \mathrm{C}$ to $356.80^{\circ} \mathrm{C}$. When the $\mathrm{CH}_{4}$ content increased by $30 \%$, the critical temperature decreased from $461.50^{\circ} \mathrm{C}$ to $93.10^{\circ} \mathrm{C}$. Once the critical temperature decreased below the formation temperature, the 


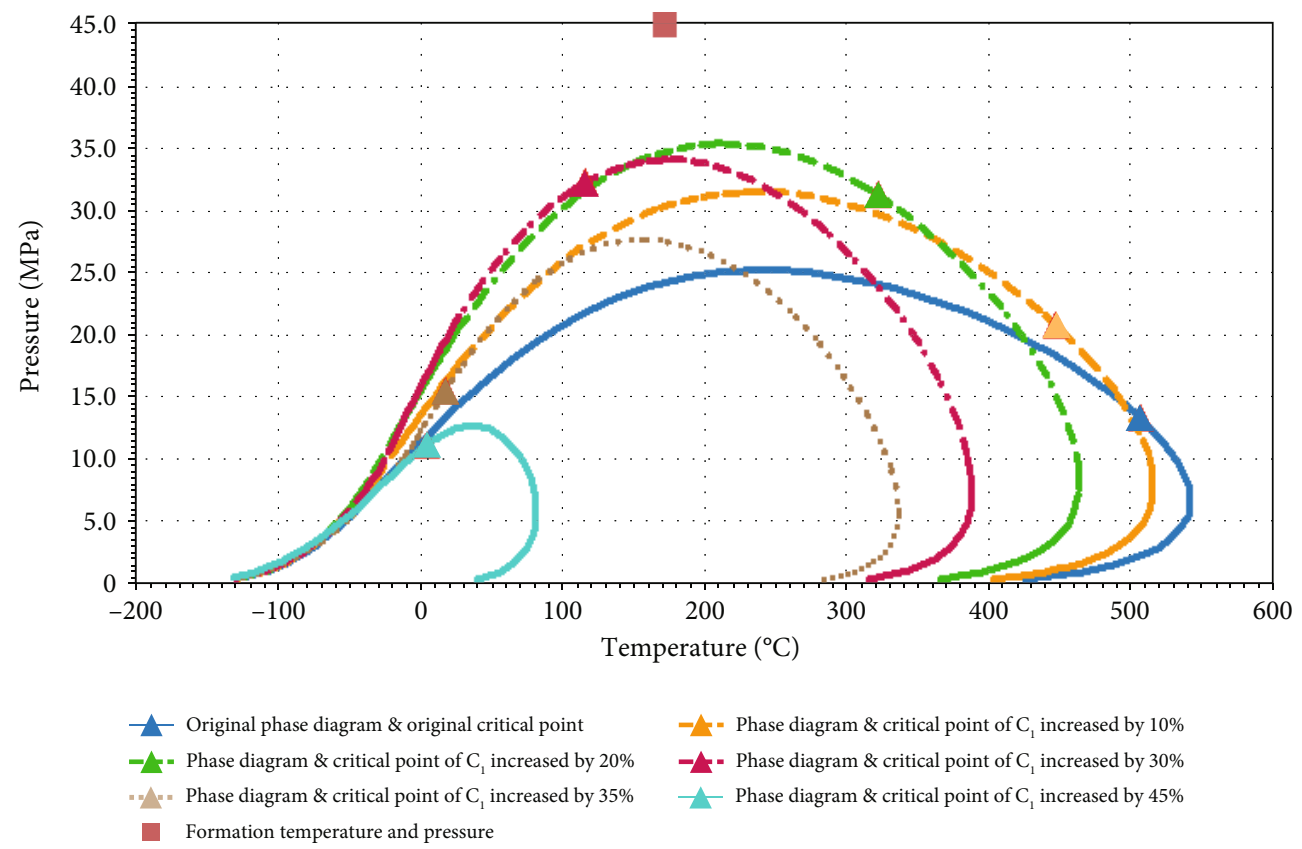

FIGURE 11: Change process of phase diagram with the increase of $\mathrm{CO}_{2}$ content in the BZ19-6 gas field. If $\mathrm{CO}_{2}$ content is increased by $10 \%$, $20 \%, 30 \%, 35 \%$, and $45 \%$, the critical temperature is decreased from $506.10^{\circ} \mathrm{C}$ to $448.10^{\circ} \mathrm{C}, 321.30^{\circ} \mathrm{C}, 115.7^{\circ} \mathrm{C}, 20.20^{\circ} \mathrm{C}$, and $5.80^{\circ} \mathrm{C}$, respectively. Therefore, the original oil reservoir easily transformed into the condensate gas reservoir.

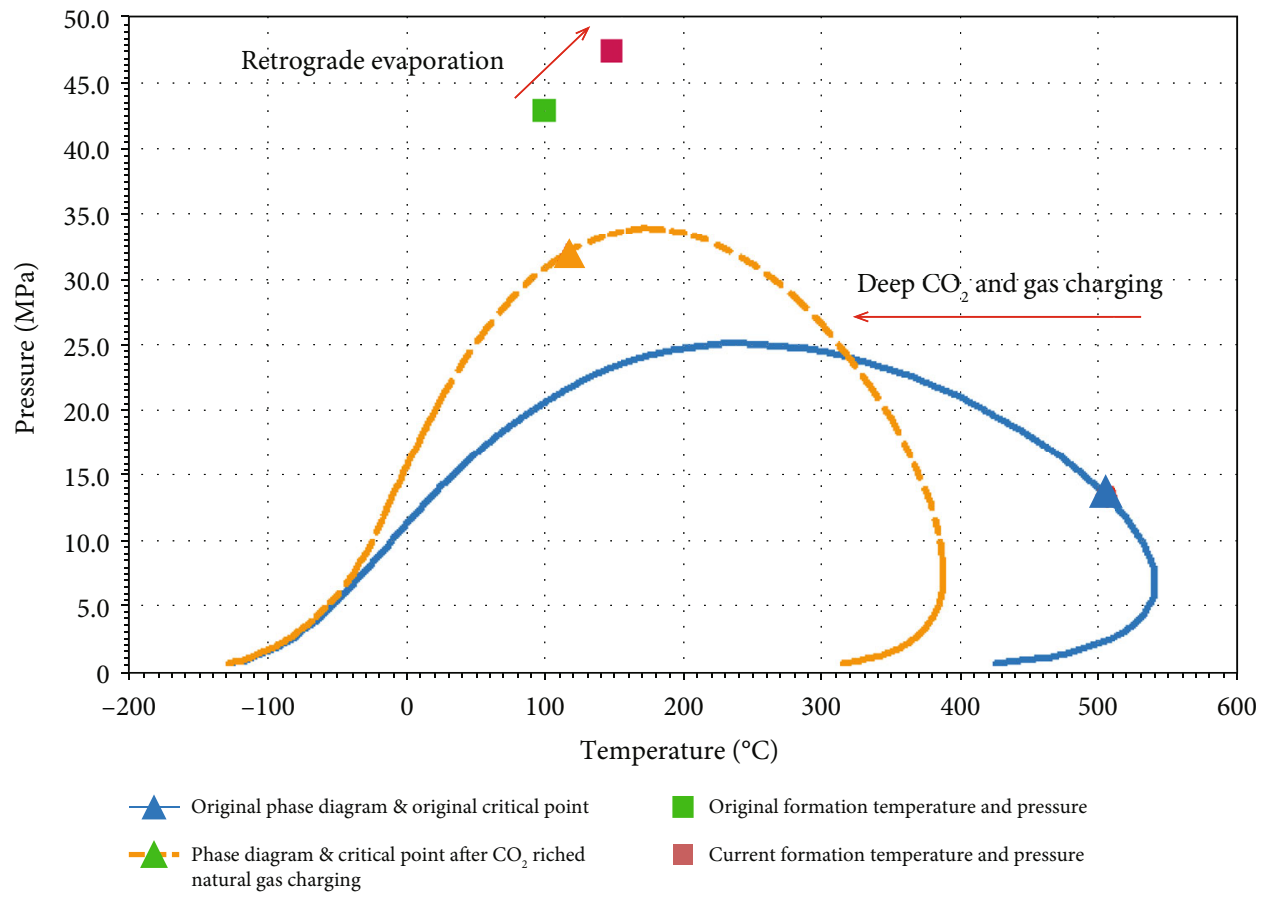

FIGURE 12: Schematic diagram of oil and gas phase behavior genesis from BZ19-6 condensate gas reservoir, it may be a secondary condensate gas reservoir, formed by retrograde evaporation, inorganic $\mathrm{CO}_{2}$ charging from the deep mantle, and late natural gas invasion in order.

hydrocarbon fluid changed from the liquid phase to the condensate gas phase, forming a gas invasion condensate gas reservoir.

The phase behavior of the condensate gas reservoirs is closely related to the gas invasion intensity. When the gas invasion intensity is high, the reservoir would be a high GOR pure condensate gas reservoir without the oil ring; when the gas invasion intensity is low, it would be a low GOR condensate gas reservoir with oil rings. Therefore, the intensity of the gas invasion affects the phase behavior of 


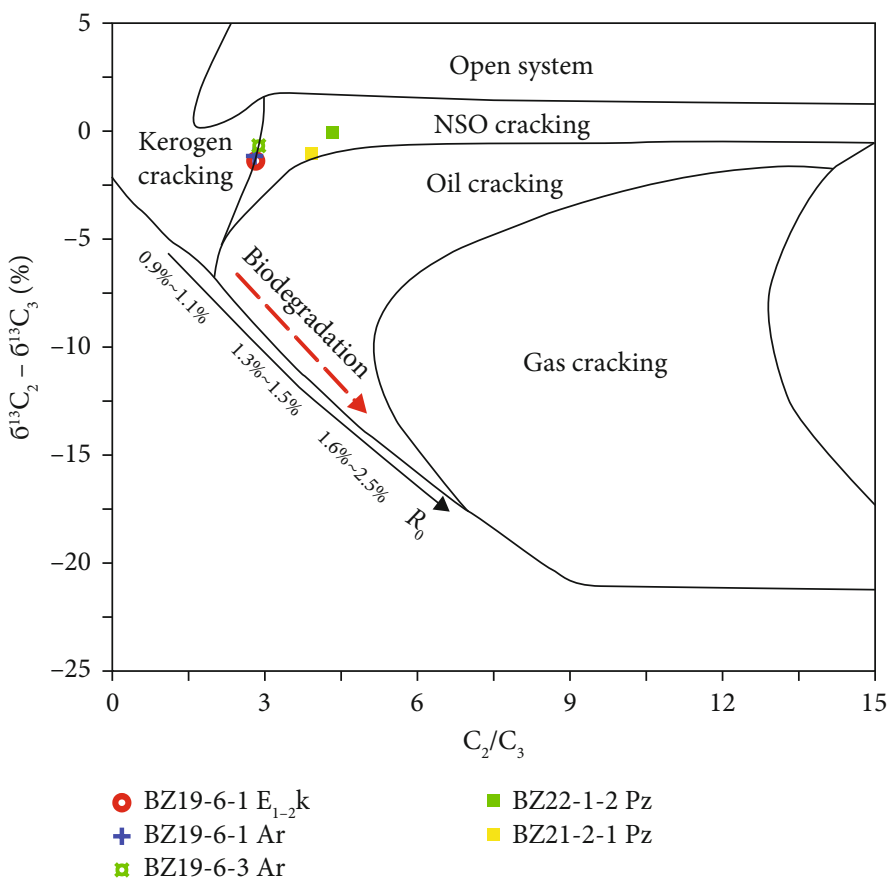

FIGURE 13: Genesis of the natural gas between in BZ19-6 and BZ21-22 structures (after [47]). The results suggest that the gas genesis in BZ2122 structure belongs to NSO (nitrogen, sulfur, and oxygen organic compounds) macromolecular compounds cracked gas, where the gas in BZ19-6 structure belongs to Kerogen cracked gas.

oil and gas. The gas invasion intensity of the BZ19-6 condensate gas reservoir is relatively weak, implying that it is a condensate gas reservoir with oil rings with an average GOR of $1269 \mathrm{~m}^{3} / \mathrm{m}^{3}$.

4.1.3. Mantle-Derived Inorganic $\mathrm{CO}_{2}$ Charging. The average $\mathrm{CO}_{2}$ content of the BZ19-6 condensate gas reservoir was $11.24 \%$, and the carbon isotope value of $\mathrm{CO}_{2}$ ranged from $-3.6 \%$ to $-7.0 \%$, implying that $\mathrm{CO}_{2}$ is an inorganic gas. The $\delta^{13} \mathrm{C}_{\mathrm{CO} 2}$ and ${ }^{3} \mathrm{He} /{ }^{4} \mathrm{He}(\mathrm{Ra})$ values confirmed that $\mathrm{CO}_{2}$ is an inorganic gas derived from the volcanic mantle (Figure 10), primarily from $\mathrm{CO}_{2}$-rich mantle degassing [36].

The phase behavior of the hydrocarbon fluid is affected by the increase in the $\mathrm{CO}_{2}$ content [40]. PVTsim20 software was used to simulate the change characteristics of the hydrocarbon phase behavior with increasing $\mathrm{CO}_{2}$ content [41], as shown in Figure 10. As the $\mathrm{CO}_{2}$ content increased, the critical temperature of hydrocarbons decreased, the critical pressure and saturation pressure increased, the critical point shifted from right to left, and the phase diagram changed to light characteristics (shrinking to the left). When the $\mathrm{CO}_{2}$ content increased by $30 \%$, the critical temperature decreased from $506.10^{\circ} \mathrm{C}$ to $115.70^{\circ} \mathrm{C}$, and the original oil reservoir transformed into a condensate gas reservoir (Figure 11). The increase in the $\mathrm{CO}_{2}$ content is conducive to the formation of the condensate gas reservoir. The simulation results are consistent with the mercury-free visual DBR-PVT experiment by Hou et al. [42]. The technology of $\mathrm{CO}_{2}$ injection to enhance oil recovery in the later stage of condensate gas reservoir development is a practical application based on this theory. It can increase natural gas production by at least 1.39 times compared with the water flooding mode $[43,44]$.
Considering with the above factors, the BZ19-6 condensate gas reservoir may be a secondary condensate gas reservoir formed by retrograde evaporation, inorganic $\mathrm{CO}_{2}$ charging from the mantle, and late natural gas invasion. The changes in the phase behavior of the hydrocarbon are shown in Figure 12. Retrograde evaporation was caused by the burial depth and temperature increase since the Neogene. Concurrently, a large amount of natural gas and mantlederived inorganic $\mathrm{CO}_{2}$ was charged into the early formed oil reservoirs at the end of the upper Minghuazhen deposition $(2 \mathrm{Ma} \mathrm{BP})$. As a result, the content of gaseous hydrocarbons $\left(\mathrm{C}_{1}+\mathrm{CO}_{2}\right)$ increased, which provided a material basis for the liquid hydrocarbon dissolving in the gaseous hydrocarbon in the reservoir, and significantly reduced the critical temperature of the hydrocarbon system. When the critical temperature was below the formation temperature, it shifted into the critical condensate temperature range and formed the BZ19-6 condensate gas reservoir.

\subsection{Comparison between BZ19-6 and BZ21-22 Gas Reservoirs}

4.2.1. Differences in Composition and Genesis of Natural Gas. The BZ21-22 structure is located to the east of the BZ19-6 structure (Figure 1). In recent years, numerous natural gas reserves have been discovered in the buried hills of Ordovician carbonate rocks in the BZ21-22 structure. The average contents of $\mathrm{C}_{1}, \mathrm{C}_{2-6}, \mathrm{C}_{7+}$, and $\mathrm{CO}_{2}$ in the BZ19-6 structure were $66.80 \%, 14.65 \%, 7.31 \%$, and $24 \%$, respectively, according to the PVT experimental results. Moreover, the natural gas of BZ19-6 was primarily a product of high-maturity source rock $\left(R_{\mathrm{o}}: 1.61-1.85 \%\right)$. Component analysis of the natural gas of the BZ21-22 structure revealed that the content 


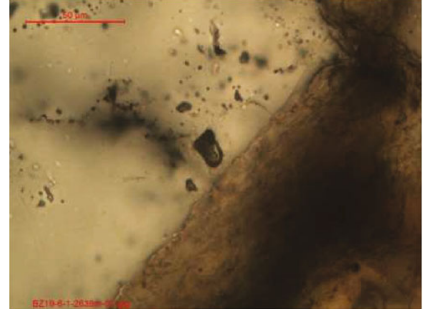

(a1)

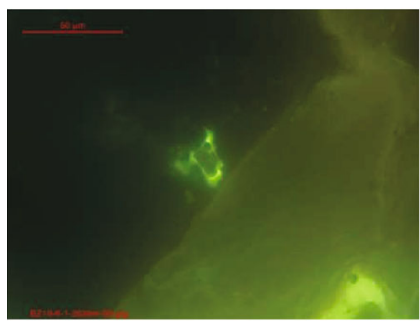

(a2)

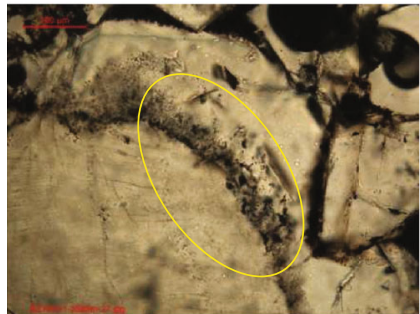

(d1)

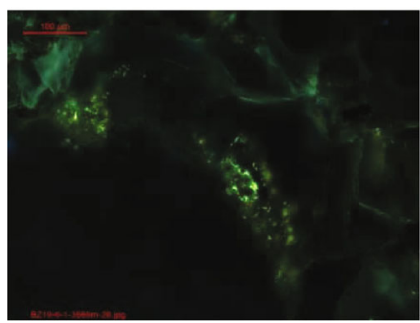

(d2)

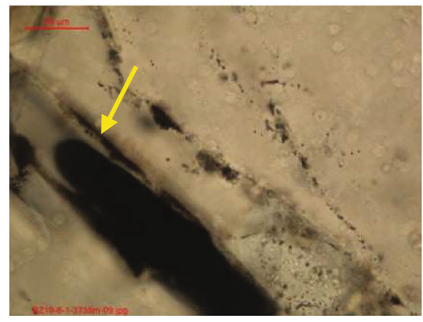

(g)

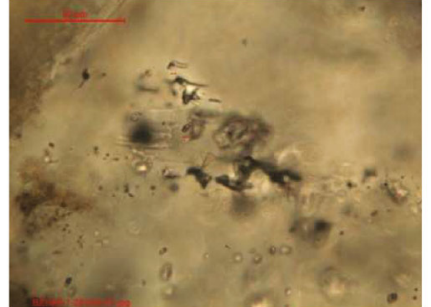

(b1)

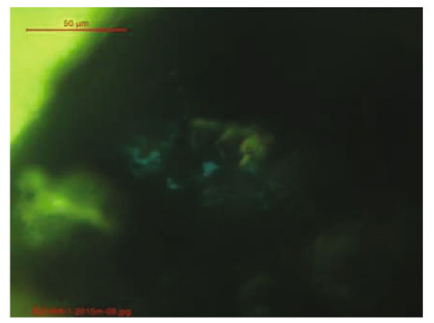

(b2)

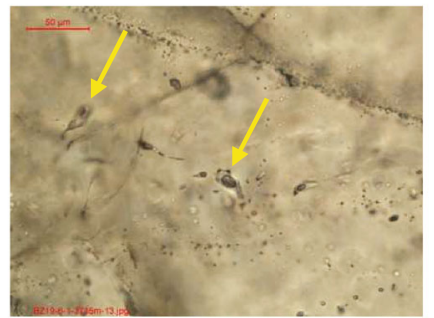

(e1)

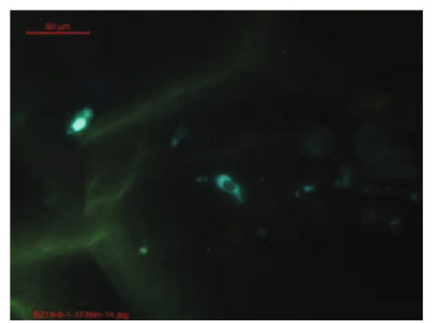

(e2)

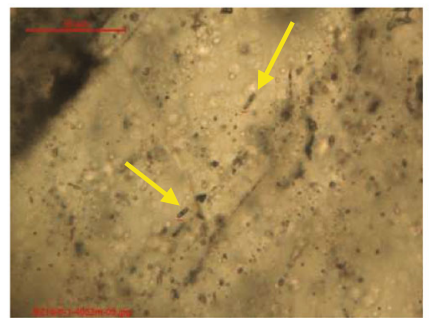

(h)

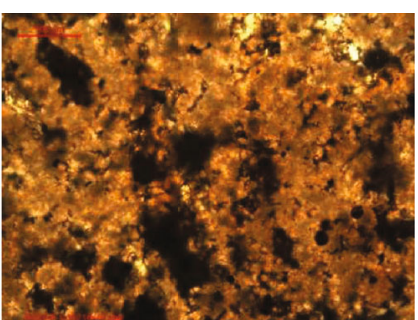

(c1)

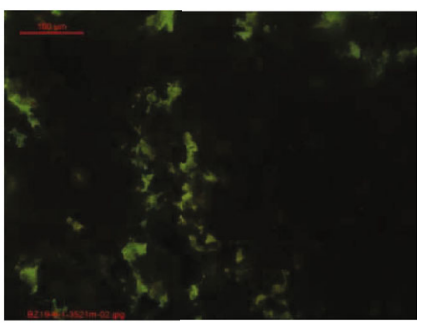

(c2)

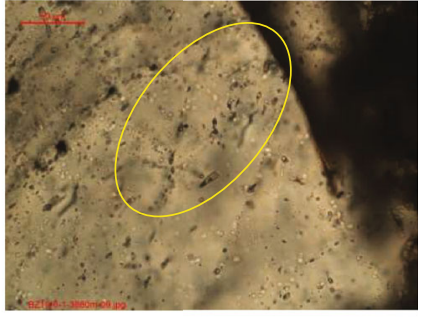

(f1)

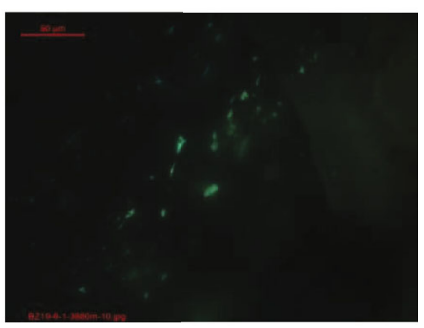

(f2)

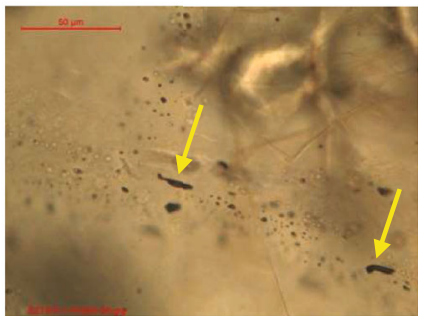

(i)

FIGURE 14: Fluorescence microscopic characteristics of fluid inclusions in different strata in BZ19-6-1 well. (a1, a2) $\mathrm{N}_{1} \mathrm{~g}, 2639 \mathrm{~m}$, fine sandstone, light yellow-gray light oil and gas inclusions in the quartz microcracks showing green fluorescence. (b1, b2) $\mathrm{E}_{3} \mathrm{~d}_{1}, 2815 \mathrm{~m}$, fine sandstone and the colorless and gray gas inclusions in the quartz microcracks showing blue fluorescence. (c1, c2) $\mathrm{E}_{3} \mathrm{~s}_{3} \mathrm{~L}, 3521 \mathrm{~m}$, light brown asphalt in the microcracks showing yellow-green fluorescence. (d1, d2) $\mathrm{E}_{3} \mathrm{~s}_{3}{ }^{\mathrm{L}}, 3585 \mathrm{~m}$, light yellow-gray light oil and gas inclusions in the secondary enlarged edge of quartz showing green fluorescence. (e1, e2) $E_{1-2} \mathrm{k}, 3735 \mathrm{~m}$, glutenite, gray light oil and gas inclusions in quartz grain microcracks showing blue fluorescence. (f1, f2) $\mathrm{E}_{1-2} \mathrm{k}, 3880 \mathrm{~m}$, light yellow-gray light oil inclusions in the quartz microcracks showing green fluorescence. $(\mathrm{g}) \mathrm{E}_{1-2} \mathrm{k}, 3735 \mathrm{~m}$, dark brown heavy oil inclusions in the secondary enlarged edge of quartz. (h) Pt, $4052 \mathrm{~m}$, light brown hydrocarbon-bearing brine inclusions in the quartz microcracks. (i) $\mathrm{Pt}, 4106 \mathrm{~m}$, banded dark gas inclusions in the quartz microcracks. 


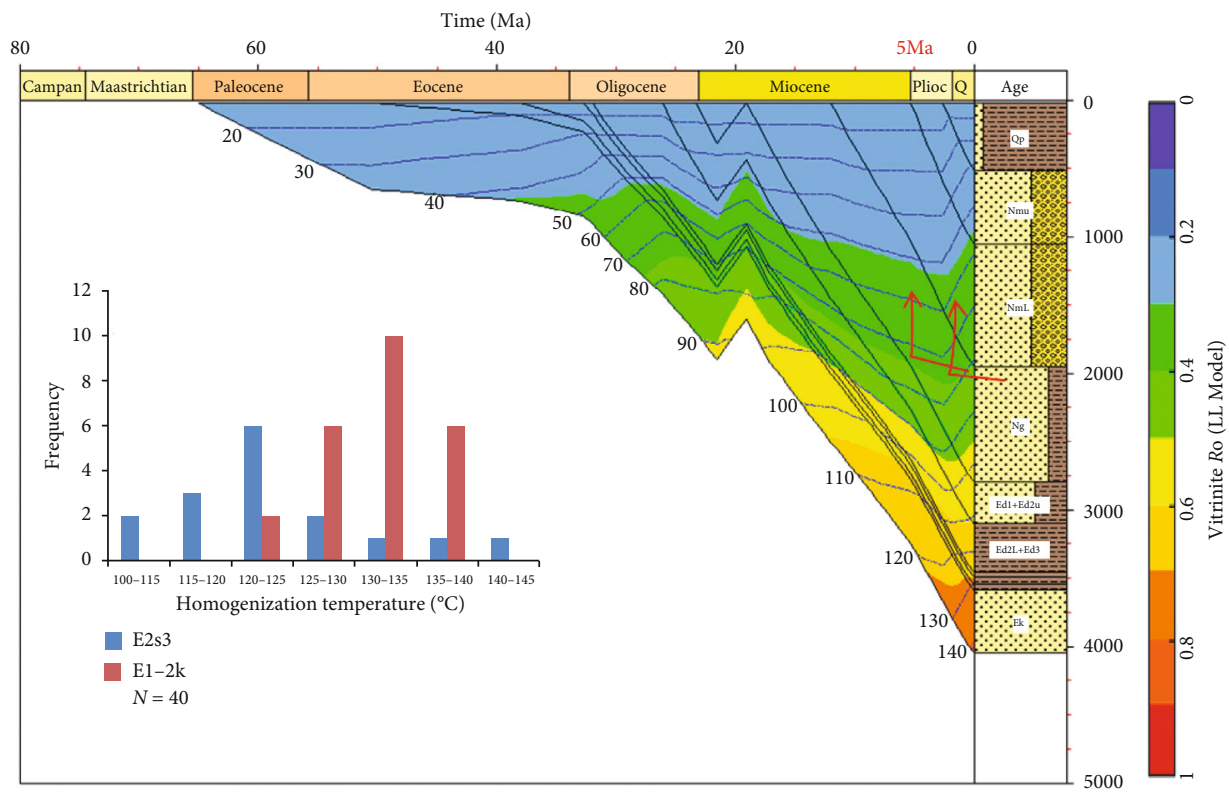

(a)

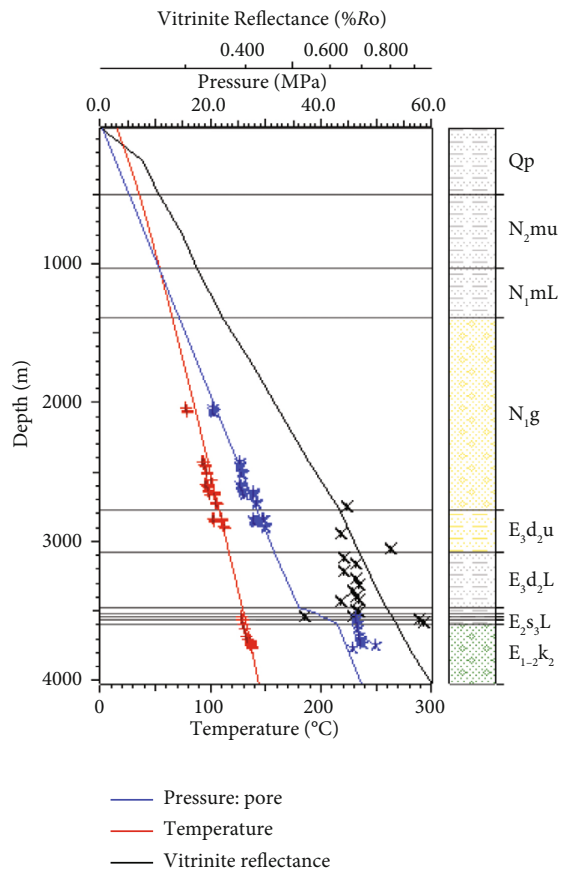

(b)

FIgURE 15: (a) Burial depth $(\mathrm{m})$ and temperature $\left({ }^{\circ} \mathrm{C}\right)$ history of well BZ19-6-1, homogenization temperature histogram of fluid inclusions of the third section of Shagejie Fm. $\left(\mathrm{E}_{2} \mathrm{~s}_{3}\right)$ and Kongdian Fm. $\left(\mathrm{E}_{1-2} \mathrm{k}\right)$ sandstones in the BZ19-6-1 well. Their homogenization temperature peak is from 120 to $125^{\circ} \mathrm{C}$, and 130 to $135^{\circ} \mathrm{C}$, which corresponds to main accumulation period after 5 and $2 \mathrm{Ma} \mathrm{BP}$, respectively, showing evidently late and rapid accumulation. (b) The one-dimensional simulation results are calibrated with measured temperature, pressure, and vitrinite reflectance data, and the simulation results are highly consistent with the measured ones.

of $\mathrm{CH}_{4}$ was $59.6 \%, \mathrm{C}_{2-6}$ was $5.34 \%$, with a minute amount of $\mathrm{C}_{7+}$, and $\mathrm{CO}_{2}$ content as high as $34.6 \%$. Moreover, the maturity of natural gas of BZ21-22 was substantially higher than that of BZ19-6, and the $R_{\mathrm{o}}$ was distributed in the range of $1.61-2.73 \%$ (Table 4 ). The carbon isotope value of $\mathrm{CO}_{2}$ was $-3.2 \%$, which was much higher than that of the BZ19-6 structure; however, it was of the same origin as the mantle- derived inorganic gas (Figure 9). The high content of $\mathrm{CO}_{2}$ is related to several deep and large basement faults in the BZ21-22 structure. During the Neotectonic movement, the activity of deep and large faults in the basement was enhanced, converting them into dominant channels for the migration of mantle-derived inorganic $\mathrm{CO}_{2}$. The difference in the activity of deep and large faults may result in a 


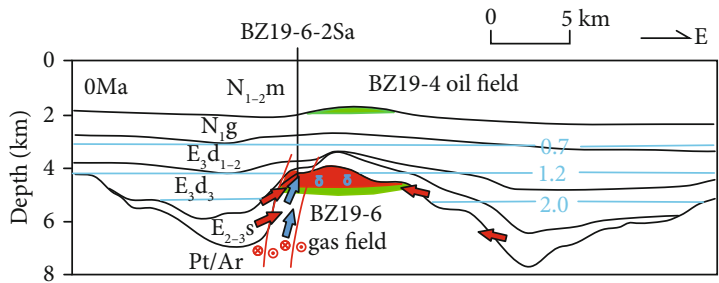

(c)

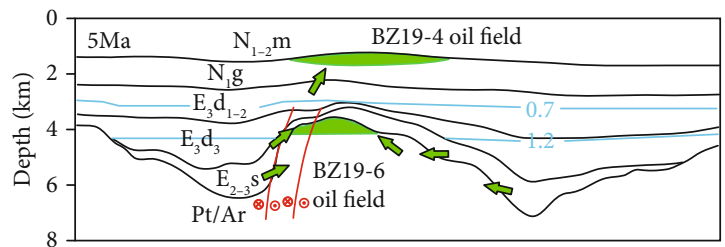

(b)

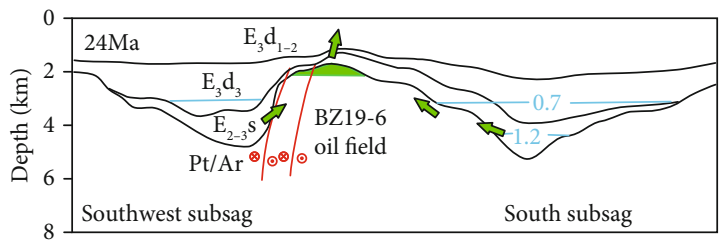

(a)

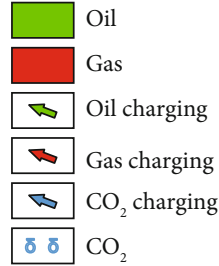

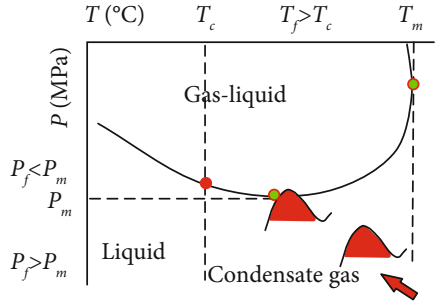
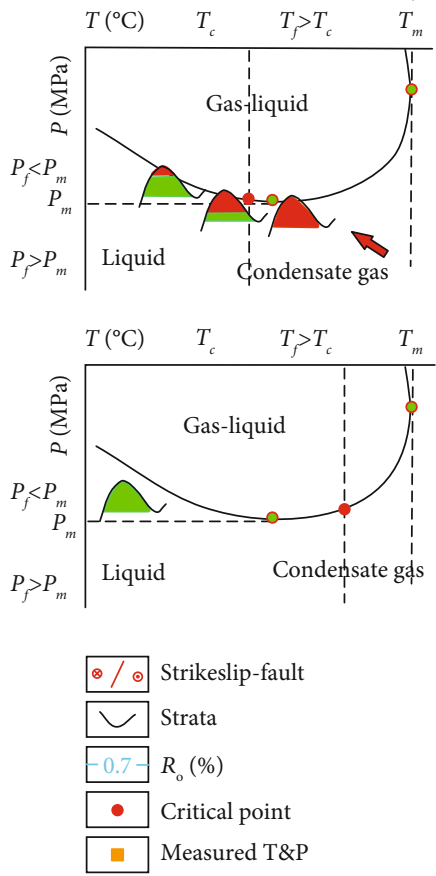
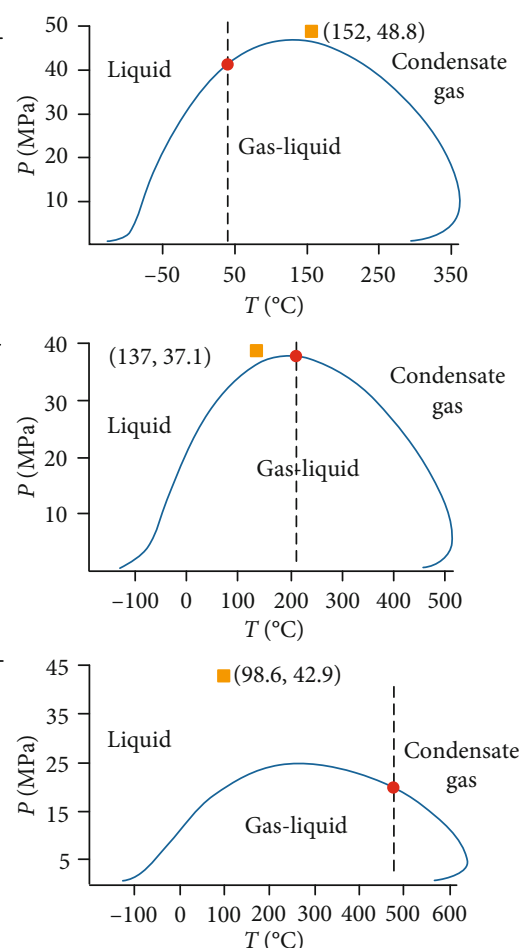

FIgURE 16: Hydrocarbon accumulation process (after [8]) and phase behavior change in the BZ19-6 buried hill during different geologic periods $(\mathrm{a}-\mathrm{c})$. Ar: Archean stratum; Pt: Proterozoic stratum; $\mathrm{E}_{2-3} \mathrm{~s}$ : Shahejie Fm.; $\mathrm{E}_{3} \mathrm{~d}$ : Dongying Fm.; N ${ }_{1-2}$ m: Minghuazhen Fm.).

difference in the content of mantle-derived inorganic $\mathrm{CO}_{2}$ in the BZ19-6 and BZ21-22 structures [45, 46].

The formation temperature of the BZ21-22 structure was as high as $173^{\circ} \mathrm{C}$, which was higher than that at the same depth in the BZ19-6 structure. This may be due to the thermal anomaly caused by the strong activity of the deep mantle-derived inorganic $\mathrm{CO}_{2}$, which promoted the maturity of the source rocks higher than that of the BZ19-6 structure. The $R_{\mathrm{o}}$ value of the Shahejie source rocks of the BZ21-22 structure was $0.1-1.6 \%$ during the main gas generation stage and that of the source rocks with burial depths $>5000 \mathrm{~m}$ was $>2.0 \%$; the $R_{\mathrm{o}}$ of the Shahejie source rocks of the BZ19-6 structure is generally $<0.9 \%$. High temperatures (more than $160^{\circ} \mathrm{C}$ ) promoted the cracking of crude oil into gas. The gas genesis of the BZ21-22 structure revealed that it is a nitrogen-sulfur-oxygen (NSO)-cracked gas (Figure 13), which is different from that of the BZ19-6 structure.

4.2.2. Differences in Genetic Mechanisms. Based on the tectonic location, natural gas composition, and genesis, the origin of pure gas reservoirs of BZ21-22 can be summarized. The mantle-derived inorganic $\mathrm{CO}_{2}$ fluid activity along the basement deep fault caused the hydrocarbon system to be rich in $\mathrm{CO}_{2}$ and substantially reduced its critical temperature.
This further induced thermal anomalies that consequently increased the maturity of the source rock during the main gas generation stage. The geothermal temperature rise caused the NSO cracking of crude oil into gas. In addition, the BZ2122 structure was located closer to the Bozhong Sag than the BZ19-6 structure. The natural gas generated in the late stage of the hydrocarbon source rock preferentially charged into the BZ21-22 structure, and the gas invasion intensity became greater than that of the BZ19-6 structure. Therefore, BZ21-22 pure gas reservoirs were formed by the combined action of deep mantle-derived inorganic $\mathrm{CO}_{2}$ fluid activity and late gas invasion.

\subsection{Hydrocarbon Accumulation Process}

4.3.1. Evidence of Fluid Inclusions. The host minerals of the inclusions in the BZ19-6 structure are mainly quartz, which occurs in quartz grain microcracks and secondary enlarged edges. They are distributed in isolated, banded, and beaded inclusions (Figures 14(a1), 14(e1), 14(d1), and 14(f1)). The hydrocarbon inclusions are light yellow, gray, and light brown as observed under a single polarized light (Figures 14(a1), 14(e1), and 14(h)). The oil inclusion is presented in green, yellow-green, and blue-white colors under UV fluorescence 
excitation (Figures 14(a2), 14(d2), 14(c2), 14(f2), and 14(e2)). There are at least two stages for the inclusions of the BZ19-6 structure: the early stage comprises low-maturity light oil inclusions with green and yellow-green fluorescence, and the late stage includes high-maturity gas-rich inclusions with blue-white fluorescence. Light brown hydrocarbon-bearing brine inclusions and dark gray gas inclusions (Figures 14(h) and 14(i)) were observed in the deep Archean quartz grain microcracks, which contain significant late natural gas charging characteristics.

4.3.2. Charging Period of Hydrocarbon. Hydrocarbon charge and accumulation in the Shijiutuo uplift in the northern Bozhong Sag rapidly occurred in the late stage, with a charging time not earlier than 5.1 Ma BP [48]. With this method, the oil and gas charging period of the BZ19-6 reservoir could be restored by the homogenization temperature and thermal evolution history of the hydrocarbon-containing brine inclusions. The reservoirs of the Kongdian Fm. and the Archean buried hill experienced at least two stages of oil and gas charging. The homogenization temperature of low-maturity light oil is $120-125^{\circ} \mathrm{C}$, which corresponds to the end of the lower Minghuazhen Fm. (5 Ma BP). The homogenization temperature of the rich gas inclusion is $130-135^{\circ} \mathrm{C}$, which corresponds to the end of the upper Minghuazhen Fm. (2 $\mathrm{Ma} \mathrm{BP}$ ). The main accumulation period was $5 \mathrm{Ma} \mathrm{BP}$, with evident late rapid accumulation characteristics (Figure 15).

4.3.3. Hydrocarbon Accumulation Process. The oil-source correlation indicates that the condensate oil and gas mainly originate from the high-maturity source rock of the third section of the Shahejie Fm. $\left(\mathrm{E}_{2} \mathrm{~s}_{3}\right)$ [9]. The BZ19-6 condensate gas reservoir is a regional overpressure mudstone enrichment model that has undergone a continuous natural gas charging process after the oil accumulates in the trap [4]. The excess pressure in mudstone is widespread, which is an important factor affecting hydrocarbon accumulation in the Bohai Bay Basin [49]. Based on the study of the BZ19-6 condensate gas reservoir genetic mechanism, the period of oil and gas charging, and comparison with the gas reservoir in the BZ21-22 structure, the hydrocarbon accumulation process of the gas reservoir of the BZ19-6 structure was analyzed. At the end of the Paleogene (24 Ma BP), the source rocks of the Bozhong Sag entered the mature stage. Hydrocarbon fluid was transported to the BZ19-6 buried hill along the fault and unconformity and accumulated into small-scale reservoirs. Due to the shallow depth $(<2000 \mathrm{~m})$ and the low diagenetic degree of the mudstone caprock of the Dongying Fm., oil and gas could escape easily (Figure 16(a)).

At the end of the lower Minghuazhen deposition (5 Ma BP), the source rocks of the Bozhong Sag entered maturity and high-maturity stage, a large amount of hydrocarbon was generated and expelled, and a large amount of crude oil began to accumulate in the BZ19-6 structure. Some crude oil migrated upward along the fault and accumulated in the shallow Guantao Fm., forming the BZ19-4 reservoirs. This was the main accumulation period since $5 \mathrm{Ma}$ (Figure 16(b)).

At the end of the upper Minghuazhen deposition (2 Ma $\mathrm{BP})$, the source rocks of the Bozhong Sag entered a highly mature stage, with the generation of a large quantity of gas. Owing to the invasion by natural gas, combined with the mantle-derived inorganic $\mathrm{CO}_{2}$ in the early reservoir, the gaseous hydrocarbon content increased and the critical temperature decreased significantly [8]. Under high-temperature and high-pressure conditions, the soluble components in the crude oil dissolved into natural gas and the heavy components precipitated to form asphalt. As a result, the early oil reservoir was transformed into a current condensate gas reservoir (Figure 16(c)).

\section{Conclusions}

(1) The BZ19-6 condensate gas reservoir is an ultra-high condensate gas reservoir. The average concentrations of $\mathrm{C}_{1}, \mathrm{C}_{2-6}$, and $\mathrm{C}_{7+}$ in the hydrocarbon fluid were $66.8 \%, 14.66 \%$, and $7.3 \%$, respectively. The $\mathrm{CO}_{2}$ content of the mantle-derived inorganic origin was as high as $11.24 \%$. The average content of ground condensate was $615.96 \mathrm{~g} / \mathrm{m}^{3}$, which indicates a gas reservoir with extremely high condensate content

(2) Based on the analysis using different methods, the hydrocarbon fluid phase type of the BZ19-6 structure was revealed to be a condensate gas reservoir with oil rings. Its genesis resulted from the retrograde evaporation caused by burial depth, temperature increase since the Neogene, inorganic $\mathrm{CO}_{2}$ charging from the deep mantle, and late natural gas invasion

(3) The hydrocarbon accumulation process of the BZ196 condensate gas reservoir can be summarized as follows: a large amount of oil accumulated at the end of the lower Minghuazhen deposition (5 Ma BP), followed by a large amount of natural gas and mantle-derived inorganic $\mathrm{CO}_{2}$ charged into the early formed oil reservoirs at the end of the upper Minghuazhen deposition (2 Ma BP). As a result, the content of gaseous hydrocarbons $\left(\mathrm{C}_{1}+\mathrm{CO}_{2}\right)$ increased, which led to large amounts of liquid hydrocarbons being dissolved in gaseous hydrocarbons, and significantly reduced the critical temperature of the hydrocarbon system. When the critical temperature is lower than the formation temperature and enters the critical condensate temperature range, secondary condensate gas reservoirs are formed

\section{Data Availability}

The data used to support the findings of this study are included within the article.

\section{Conflicts of Interest}

The authors declare that there are no conflicts of interest.

\section{Acknowledgments}

This work was supported by the Major National Science and Technology Project (No. 2017ZX05008-004-004) and the 
National Natural Science Foundation of China (project no. 41672121). The authors would like to thank the support of related data from the Research Institute of Exploration and Development, Tianjin branch of the China National Offshore Oil Limited Corporation.

\section{References}

[1] P. Weimer, R. Bouroullec, J. Adson, and S. P. J. Cossey, “An overview of the petroleum systems of the northern deepwater Gulf of Mexico," AAPG Bulletin, vol. 101, no. 7, pp. 941-993, 2017.

[2] C. Z. Jia and X. Q. Pang, "Research processes and main development directions of deep hydrocarbon geological theories," Acta Petrolei Sinica, vol. 36, no. 12, pp. 1457-1469, 2015.

[3] X. Q. Pang, C. Z. Jia, and W. Y. Wang, "Petroleum geology features and research developments of hydrocarbon accumulation in deep petroliferous basins," Petroleum Science, vol. 12, no. 1, pp. 1-53, 2015.

[4] Y.'. Xue and D. Wang, "Formation conditions and exploration direction of large natural gas reservoirs in the oil-prone Bohai Bay Basin, East China," Petroleum Exploration and Development, vol. 47, no. 2, pp. 280-291, 2020.

[5] Y. H. Xie, G. C. Zhang, P. Shen et al., "Formation conditions and exploration direction of large gas field in Bozhong depression of Bohai Bay Basin," Acta Petrolei Sinica, vol. 39, no. 11, pp. 1199-1210, 2018.

[6] H. S. Shi, Q. B. Wang, J. Wang et al., "Discovery and exploration significance of large condensate gas fields in BZ19-6 structure in deep Bozhong sag," China Petroleum Exploration, vol. 24, no. 1, pp. 36-45, 2019.

[7] J. Fujie and P. Xiongqi, "Quantitative evaluation of hydrocarbon resource potential and its distribution in the Bozhong Sag and surrounding areas, Bohai Bay Basin," Petroleum Exploration and Development, vol. 38, no. 1, pp. 23-29, 2011.

[8] C. Xu, H. Yu, J. Wang, and X. Liu, "Formation conditions and accumulation characteristics of BZ19-6 large condensate gas field in offshore Bohai Bay Basin," Petroleum Exploration and Development, vol. 46, no. 1, 2019.

[9] Y. A. Xue, "The breakthrough of the deep-buried gas exploration in the Bohai Sea area and its enlightenment," Natural Gas Industry, vol. 39, no. 1, pp. 11-20, 2019.

[10] X. Y. Lv, Y. L. Jiang, and J. D. Liu, "Phase types identification and genetic analysis for Paleogene condensate gas pools in the Dongpu depression," Journal of China University of Mining \& Technology, vol. 45, no. 6, pp. 1211-1218, 2016.

[11] D. B. Yang, G. Y. Zhu, J. J. Liu, J. Su, B. Zhang, and A. G. Fei, "Distribution of global condensate gas field and major factors controlling its formation," Earth Science Frontiers, vol. 17, no. 1, pp. 339-349, 2010.

[12] H. R. Nasriani, A. A. Borazjani, M. Sinaei, and A. Hashemi, "The effect of gas injection on the enhancement of condensate recovery in gas condensate reservoirs: a comparison between a synthetic model and PVT cell results," Liquid Fuels Technology, vol. 32, no. 5, pp. 593-601, 2014.

[13] F. A. V. Ferreira, T. C. S. Barbalho, I. R. S. Araújo, H. N. M. Oliveira, and O. Chiavone-Filho, "Characterization, pressure-volume-temperature properties, and phase behavior of a condensate gas and crude oil," Energy \& Fuels, vol. 32, no. 4, pp. 5643-5649, 2018.
[14] D. L. Katz, "Overview of phase behavior in oil and gas production," Journal of Petroleum Technology, vol. 35, no. 6, pp. 1205-1214, 1983.

[15] C. H. Whitson and M. R. Brule, "Phase behavior," SPE Monograph, vol. 20, 2000.

[16] B. P. Tissot, B. Durand, and A. Combaz, "Influence of nature and diagenesis of organic matter in formation of petroleum," AAPG Bulletin, vol. 58, no. 3, pp. 499-506, 1974.

[17] Y. K. Kharaka, "Petroleum formation and occurrence: a new approach to oil and gas exploration," Earth-Science Reviews, vol. 16, no. 16, pp. 372-373, 1978.

[18] L. R. Snowdon and T. G. Powell, "Immature oil and condensate: modification of hydrocarbon generation model for terrestrial organic matter," AAPG Bulletin, vol. 66, no. 6, pp. 775778, 1982.

[19] A. Danesh, "PVT and phase behavior of petroleum reservoir fluid," Developments in Petroleum Science, vol. 11, no. 1, pp. 1-3, 1998.

[20] Zhou Xingxi, Wang Hongjun, Chen Yicai, and Xu Zhiming, "The study on the contributing factors of phase state of gas condensate : examples from Tarim Basin," Marine and Petroleum Geology, vol. 15, no. 1, pp. 21-31, 1998.

[21] L. Chen, G. Y. Zhu, B. Zhang, Z. G. Wen, and Y. G. Wang, "Control factors and diversities of phase state of oil and gas pools in the Kuqa petroleum system," Acta Geologica Sinica, vol. 86, no. 2, pp. 484-496, 2012.

[22] J. Q. Chen, X. Q. Pang, Z. X. Jiang, and H. Pang, "Controlling factors and phase state of hydrocarbons in the Upper Ordovician of the Tazhong area, Tarim Basin," Natural Gas Geoscience, vol. 25, no. 12, pp. 1913-1924, 2014.

[23] S. C. Zhang, "An important mechanism of condensate oil and waxy oil generated," Chinese Science Bulletin, vol. 45, no. 6 , pp. 667-670, 2000.

[24] Y. A. Xue, Q. Wang, C. M. Niu, Q. Y. Miao, M. X. Liu, and J. Yin, "Hydrocarbon charging and accumulation of BZ 19-6 gas condensate field in deep buried hills of Bozhong depression, Bohai Sea," Oil \& Gas Geology, vol. 41, no. 5, pp. 891902, 2020.

[25] A. W. Hu, C. M. Niu, D. Y. Wang, H. Y. Li, T. Ye, and P. Xu, "The characteristics and formation mechanism of condensate oil and gas in Bozhong19-6 structure, Bozhong sag, Bohai Bay basin," Acta Petrolei Sinica, vol. 41, no. 4, pp. 403-411, 2020.

[26] A. W. Hu, D. Y. Wang, H. B. Yu, T. Jiang, and Z. Sun, "Genesis of natural gas and genetic relationship between the gas and associated condensate in Bozhong 19-6 gas condensate field, Bohai Bay Basin,” Oil \& Gas Geology, vol. 41, no. 5, pp. 903912, 2020.

[27] K. S. Pedersen, A. L. Blilie, and K. K. Meisingset, "PVT calculations on petroleum reservoir fluids using measured and estimated compositional data for the plus fraction," Industrial \& Engineering Chemistry Research, vol. 31, no. 5, pp. 13781384, 1992.

[28] H. Manafi, G. A. Mansoori, and S. Ghotbi, "Phase behavior prediction of petroleum fluids with minimum characterization data," Journal of Petroleum Science and Engineering, vol. 22, no. 2, pp. 67-93, 1999.

[29] M. N. Shehata, S. E. K. Fateen, and A. Bonilla-Petriciolet, "Critical point calculations of multi-component reservoir fluids using nature- inspired metaheuristic algorithms," Fluid Phase Equilibria, vol. 409, pp. 280-290, 2016. 
[30] M. Alarouj, O. Alomair, and A. Elsharkawy, "Gas condensate reservoirs: characterization and calculation of dew-point pressure," Petroleum Exploration and Development, vol. 47, no. 5, pp. 1091-1102, 2020

[31] Z. D. Sun, "Methods for determining the type of different oil and gas reservoirs fluid," Petroleum Exploration and Development, vol. 23, no. 1, pp. 69-75, 1996.

[32] China National Energy Administration, Technical requirements for determining phase behaviors of gas condensate reservoirs (SY/T 6101-2012), Petroleum Industry Press, Beijing, 2012.

[33] S. Palakodaty and P. York, "Phase behavioral effects on particle formation processes using supercritical fluids," Pharmaceutical Research, vol. 16, no. 7, pp. 976-985, 1999.

[34] J. X. Dai and H. F. Qi, "The $\delta 13 C 1-$ Ro relationship of coalderived hydrocarbon gas in China," Chinese Science Bulletin, vol. 34, no. 9, pp. 690-690, 1989.

[35] P. Shen, Y. C. Xu, X. B. Wang, D. H. Liu, Q. X. Shen, and W. H. Liu, The geochemical characteristics and gas formation mechanism of gas source rock and natural gas, Gansu Scientific \& Technical Publishers,, Gansu:, 1991.

[36] M. A. Rooney, G. E. Claypool, and H. Moses Chung, "Modeling thermogenic gas generation using carbon isotope ratios of natural gas hydrocarbons," Chemical Geology, vol. 126, no. 3-4, pp. 219-232, 1995.

[37] K. F. M. Thompson, "Fractionated aromatic petroleums and the generation of gas-condensates," Organic Geochemistry, vol. 11, no. 6, pp. 573-590, 1987.

[38] J. P. Chen, C. P. Deng, X. L. Wang et al., "Formation mechanism of condensates, waxy and heavy oils in the southern margin of Junggar Basin, NW China," Science China Earth Sciences, vol. 60, no. 5, pp. 972-991, 2017.

[39] X. H. Zhou, R. C. Zhang, H. Y. Li, B. Q. Wang, and Y. H. Guo, "Major controls on natural gas accumulations in deep-buried hills in Bozhong Sag, Bohai Bay Basin," Journal of China University of Petroleum, vol. 41, no. 1, pp. 42-50, 2017.

[40] H. Y. Chiu, R. F. Jung, M. J. Lee, and H. M. Lin, "Vapor-liquid phase equilibrium behavior of mixtures containing supercritical carbon dioxide near critical region," Journal of Supercritical Fluids, vol. 44, no. 3, pp. 273-278, 2008.

[41] D. H. Liu, X. M. Xiao, J. K. Mi et al., "Determination of trapping pressure and temperature of petroleum inclusions using PVT simulation software-a case study of Lower Ordovician carbonates from the Lunnan Low Uplift, Tarim Basin," Marine and Petroleum Geology, vol. 20, no. 1, pp. 29-43, 2003.

[42] D. L. Hou, Y. Xiao, Y. Pan, L. Sun, and K. Li, "Experiment and simulation study on the special phase behavior of Huachang near-critical condensate gas reservoir fluid," Journal of Chemistry, vol. 2016, Article ID 2742696, 10 pages, 2016.

[43] N. N. Hamidov and V. M. Fataliyev, "Experimental study into the effectiveness of the partial gas cycling process in the gascondensate reservoir development," Petroleum Science and Technology, vol. 34, no. 7, pp. 677-684, 2016.

[44] Z. Su, Y. Tang, H. Ruan, Y. Wang, and X. Wei, "Experimental and modeling study of CO2: Improved gas recovery in gas condensate reservoir," Petroleum, vol. 3, pp. 87-95, 2017.

[45] J. Li, H. Y. Zou, X. H. Zhou, G. Wei, X. B. Zhuang, and J. Q. Tian, "Carbon dioxide origin and the main controls over its distribution in Bohai area," China Offshore Oil and Gas, vol. 24, no. 2, pp. 19-22, 2012.
[46] S. M. Mohammedyasin, S. J. Lippard, K. O. Omosanya, S. E. Johansen, and D. Harishidayat, "Deep-seated faults and hydrocarbon leakage in the Snøhvit Gas Field, Hammerfest Basin, Southwestern Barents Sea," Marine and Petroleum Geology, vol. 77, pp. 160-178, 2016.

[47] B. B. Bernard, J. M. Brooks, and W. M. Sackett, "Light hydrocarbons in recent Texas continental shelf and slope sediments7," Journal of Geophysical Research, vol. 33, no. 8, pp. 4053-4061, 1978.

[48] Q. Wang, H. Y. Zou, F. Hao et al., "Petroleum charge and entrapment along active faults: study of the accumulation mechanism of the Qinhuangdao 29 oil field on the slope of the Shijiutuo uplift, Bohai Sea," AAPG Bulletin, vol. 100, no. 10, pp. 1541-1560, 2016.

[49] X. Xie, C. M. Bethke, S. Li, X. Liu, and H. Zheng, "Overpressure and petroleum generation and accumulation in the Dongying Depression of the Bohaiwan Basin, China," Geofluids, vol. 1, no. 4, pp. 257-271, 2010. 